\title{
EL EFECTO DEL “CORTO” SOBRE LA ESTRUCTURA DE TASAS DE INTERÉS
}

\author{
Sara Gabriela Castellanos*
}

Junio de 2000

Documento de Investigación No. 2000-1

\section{Dirección General de Investigación Económica}

BANCO DE MÉXICO

\footnotetext{
* Estoy en deuda con Moisés Schwartz, Alejandro Díaz de León y Alejandro Werner por sus sugerencias y explicaciones sobre la instrumentación de política monetaria, con Daniel Garcés y Lorenza Martínez por muchas conversaciones sobre estimación y aspectos técnicos de los datos y con Eduardo Camero por su excelente asistencia. También agradezco muchas observaciones y sugerencias que recibí de los participantes de los seminarios de economía del Banco de México y del Colegio de México. Todos los errores restantes son responsabilidad de la autora. Las opiniones contenidas en este trabajo corresponden exclusivamente a la autora y no necesariamente reflejan las del Banco de México.
} 


\title{
EL EFECTO DEL “CORTO” SOBRE LA ESTRUCTURA DE TASAS DE INTERÉS
}

\author{
Sara Gabriela Castellanos \\ Banco de México \\ sgcastel@banxico.org.mx
}

Junio de 2000

Documento de Investigación No. 2000-1

\begin{abstract}
Resumen
En este documento se realiza un análisis empírico para medir el impacto que tiene la política monetaria del Banco de México, a través de la variación en su objetivo de saldos acumulados en las cuentas corrientes con la banca, sobre la estructura de tasas de interés. Nos concentramos en la tasa de interés de fondeo y en las tasas de interés de los CETES a 28, 91, 182 y 364 días de las subastas primarias. Además del objetivo de saldos acumulados, los modelos de determinación de las tasas de interés que se analizan contienen el tipo de cambio, la tasa de interés de los bonos de EU, el diferencial de tasas del bono Brady de México e índices de las bolsas de valores de algunos países extranjeros. Para las tasas de interés de los CETES, además de estas variables se incluye la diferencia respectiva con la tasa de interés de fondeo, a fin de considerar la dinámica de ajuste de largo plazo de las tasas de interés, a través de modelos de corrección de error. Los resultados, en general, muestran que una reducción en el objetivo de los saldos acumulados o "corto" está asociado a un incremento estadísticamente significativo en las tasas de interés, efecto que tiende ser mayor en las tasas de más corto plazo. Sin embargo, el análisis indica que la magnitud de este efecto ha cambiado a lo largo del periodo de análisis, mostrando inestabilidad a partir de junio de 1998.
\end{abstract}

Clasificación JEL: E52, E58 


\section{Introducción}

El objetivo de este trabajo es analizar el impacto de la política monetaria del Banco de México mediante la variación en su objetivo de saldos acumulados sobre la estructura de tasas de interés en el mercado de dinero, como un paso más para mejorar el entendimiento del primer eslabón del mecanismo de transmisión de la política monetaria. El estudio se concentra en la tasa de interés de fondeo diaria y en las tasas de interés de los Certificados de Tesorería (CETEs) de la subasta primaria semanal.

Un banco central sólo puede modificar la cantidad de dinero indirectamente, en la medida en que sea capaz de influir sobre la demanda de dinero. Uno de los canales para alterar la demanda de dinero consiste en influir, precisamente, sobre las tasas de interés. Mediante la política de liquidez del banco central se determinan precios y cantidades en el mercado de dinero, es decir, las tasas de interés y la liquidez de los bancos comerciales. Los bancos comerciales a su vez ajustan su oferta de crédito y su propio refinanciamiento, afectando los mercados de crédito y de capitales; esto es, determinando nuevas tasas de interés bancarias, el nivel de tipo de cambio, el rendimiento de las acciones y el volumen de crédito. Finalmente, los demás agentes ajustan sus decisiones de consumo, ahorro e inversión; es decir, determinando precios, salarios, empleo, producción e inversión en los mercados de bienes y factores. El entendimiento del proceso de transmisión de política monetaria es fundamental para su instrumentación apropiada.

En primer lugar se estudia el comportamiento de la tasa de interés de fondeo. Se estima un modelo lineal de determinación de la tasa de interés, utilizando información diaria de la tasa de fondeo, el tipo de cambio peso-dólar, la tasa de interés del bono del tesoro a 30 años de Estados Unidos, el diferencial de tasas del bono Brady ${ }^{1}$ de México y algunos índices de las bolsas de valores de países extranjeros. En general, los resultados de esta estimación coinciden con los que se reportan en otros estudios semejantes para México: la tasa de fondeo sube en respuesta a una reducción en el saldo objetivo, a una depreciación del tipo de cambio, a un aumento en la tasa de interés del bono de Estados Unidos y a un incremento en el diferencial de tasas del bono Brady (el cual es una medida de riesgo soberano).

Por ejemplo, los resultados de un modelo lineal estimado a través de mínimos cuadrados ordinarios (MCO) para el periodo de enero de 1996 a enero de 2000 indican que una reducción en el saldo objetivo de 20 millones de pesos está asociado a un incremento en la tasa de fondeo de 150 puntos base y una depreciación del tipo de cambio de $1 \%$ a un incremento de 45 puntos base, magnitudes que coinciden con las que reportan estudios anteriores. Asimismo, se detecta que cambios en los índices de las bolsas de Rusia y de Brasil están asociados a cambios en la tasa de fondeo, lo cual es evidencia de contagio ante variaciones en los índices de la bolsa de valores de países extranjeros. Sin embargo, un análisis más meticuloso de estos resultados revela algunos problemas con los estimadores de mínimos cuadrados ordinarios. En particular, el efecto asociado al corto es inestable a partir de junio de 1998.

\footnotetext{
${ }^{1}$ Esta variable se define como la diferencia entre el rendimiento del bono Brady de México y el rendimiento del Bono del Tesoro de EEUU a 30 años.
} 
Un análisis de regresiones rodantes, ${ }^{2}$ en el que explícitamente se admite que los coeficientes de una regresión varíen en el tiempo, nos permite seguir mejor la evolución de los coeficientes entre febrero de 1998 y enero de 2000. Encontramos que en ese periodo el efecto total asociado al anuncio de un cambio en el objetivo de saldos acumulados de un millón de pesos fluctúa entre 0.083 puntos porcentuales y cero y tiene un valor promedio de -0.027 puntos porcentuales. En consecuencia, un "corto" de 20 millones de pesos está asociado a un incremento promedio de 54 puntos base en la tasa de fondeo.

Para analizar las tasas de interés primarias de los CETEs a 28, 91, 182 y 364 días, en vez de estimar un modelo de determinación de la tasa de interés de una sola ecuación, estimamos un modelo de corrección de error tomando como tasa de interés de corto plazo la tasa de fondeo. Los resultados que se obtienen de estas estimaciones son congruentes con la teoría económica: la hipótesis de que el diferencial de tasas es estacionario, de manera que no persisten oportunidades de arbitraje en el largo plazo, no es rechazada por los datos. También se observa que el coeficiente del término de corrección de error en la ecuación de los CETES se reduce en valor absoluto conforme se extiende el plazo de 28 a 364 días, lo cual sugiere una velocidad de ajuste ante choques exógenos mayor en las tasas de más corto plazo. Por ejemplo, el $99 \%$ de una desviación del equilibrio de largo plazo entre la tasa de interés a 28 días y la tasa de fondeo se asimila aproximadamente en 10 semanas mientras que el 99\% de una desviación entre la tasa de interés a 364 días y la tasa de fondeo se asimila aproximadamente en 36 semanas.

Los resultados para el "corto", el tipo de cambio y el resto de las variables explicativas de los modelos de corrección de error coinciden, en general, con los ya mencionados. Cabe destacar que los coeficientes significativos asociados al objetivo de saldos acumulados son mayores en los modelos para las tasas de interés a 28 y a 91 días que en los modelos para las tasas de interés a 182 y 364 días. Esto sugiere que un "corto" hace menos empinada a la curva de rendimientos en el corto plazo, lo cual es indicativo de que la aplicación del "corto" reduce las expectativas de inflación futura. No obstante, el conjunto de variables independientes utilizadas en este ejercicio tienen un poder explicativo bajo para la tasa de interés de más largo plazo.

El resto del documento se estructura de la siguiente manera. La sección 2 describe brevemente el régimen monetario que opera en México desde 1995. La sección 3 presenta el modelo simple de determinación de la tasa de interés de fondeo que estimamos primero a través de un modelo de MCO. En la sección 3.2 se estima el modelo utilizando toda la muestra y en la sección 3.3 se estiman regresiones rodantes tomando para la estimación inicial datos de febrero de 1996 a febrero de 1998 debido a que en ese lapso la regresión tiene características adecuadas, especialmente, respecto de la estabilidad de los coeficientes. La sección 3.4 examina con mayor detenimiento la relación entre el tipo de cambio y la tasa de interés de fondeo, así como su interacción con el saldo objetivo mediante el examen de matrices de correlación, de pruebas de causalidad de Granger y de vectores autorregresivos con estas tres variables. La sección 4 contiene las estimaciones para las tasas de interés de los CETEs de los modelos de corrección de

${ }^{2}$ Del inglés, rolling regressions. 
error. Finalmente, la sección 5 describe algunas extensiones potenciales y presenta las conclusiones principales del trabajo.

\section{La política monetaria en México entre 1995 y 2000: el régimen de saldos acumulados}

En esta sección se realiza una breve descripción del régimen de política monetaria de México para que este trabajo esté autocontenido para aquellos lectores poco familiarizados con el tema. Un lector más interesado puede acudir a las descripciones más completas sobre el régimen que hacen Gil (1997 y 1998), O’Dogherty (1997) y Carstens y Werner (1999), o bien a los Informes Anuales del Banco de México.

La adopción del régimen cambiario de libre flotación en enero de 1995, convirtió de facto a la política monetaria en el ancla nominal de la economía. Por otra parte, la alta inflación y la contracción de la economía real que siguieron a la adopción de esta medida durante la primera mitad de 1995, mismas que crearon expectativas altamente volátiles respecto de las perspectivas económicas del país, hicieron poco aconsejable adoptar como instrumento de política monetaria la tasa de interés nominal, como ocurre en los países con baja inflación como Estados Unidos, Canadá, Australia y Japón. En consecuencia, se decidió que la política del Instituto Central de satisfacer la demanda de dinero, fuese complementada con una tasa de interés determinada libremente por el mercado y por acciones discrecionales a través de la variación en el objetivo de saldos acumulados de las cuentas corrientes de las instituciones de crédito con el Banco de México.

La política monetaria de México se opera principalmente a través del control de la liquidez que el Banco de México inyecta o retira mediante subastas diarias con los bancos comerciales. El régimen de saldos acumulados establece periodos de cómputo de 28 días naturales y está diseñado para inducir a las instituciones de crédito a no mantener en promedio saldos positivos, ni incurrir en sobregiros en sus cuentas, así como para que procuren compensar con otros bancos sus sobrantes y faltantes de recursos a tasas de interés de mercado. Por esta última razón, durante el periodo de cómputo, el Banco de México no remunera los saldos positivos ni cobra interés alguno por los sobregiros que se registren al cierre del día cuando éstos se encuentren dentro de ciertos límites, a los cuales se hace referencia más adelante. Al cierre del periodo de cómputo, el Banco de México cobra por los saldos acumulados negativos una tasa de interés equivalente a dos veces una tasa representativa de las condiciones prevalecientes en el mercado de dinero (actualmente se utiliza para este fin la tasa de CETES al plazo de 28 días en colocación primaria). Esto, con la finalidad de que sean parecidos los costos en que incurran los bancos cuya cuenta registre un saldo acumulado positivo al final del periodo de cómputo y los que deban pagar por no haber compensado sus sobregiros. Los costos son similares ya que las instituciones con saldos acumulados positivos incurren en un costo de oportunidad, por no haber invertido estos recursos, equivalente a la tasa de mercado. Por su parte, los bancos con saldos acumulados negativos deben pagar al cierre del periodo dos veces la tasa representativa del mercado, pero a cambio se benefician de la inversión de los recursos obtenidos mediante el 
sobregiro. De lo anterior se concluye que el costo neto es, en ambos casos, aproximadamente una vez la tasa de interés de mercado.

El Banco de México da a conocer la cantidad a la que pretende llevar el "saldo acumulado de saldos diarios totales" de las cuentas corrientes de la banca a la apertura del siguiente día hábil. ${ }^{3}$ Un objetivo de saldos acumulados igual a cero sería indicativo de la intención del Banco Central de satisfacer, a tasas de interés de mercado, la demanda de billetes y, por tanto, proporcionar los recursos necesarios para que ningún banco se vea obligado a incurrir en sobregiros o a acumular saldos positivos no deseados al finalizar el periodo de cómputo. Esto sería indicación de una política monetaria neutral. A su vez, un objetivo de saldos acumulados negativo o "corto" señalaría la intención del Banco Central de no proporcionar a la banca los recursos suficientes a tasas de interés de mercado, obligando así a una o varias instituciones de crédito a obtener una parte de los recursos requeridos a través del sobregiro en sus cuentas corrientes. Esto último, abstrayendo de otras influencias, provoca un alza en las tasas de interés, ya que las instituciones tratarán de evitar pagar la elevada tasa de sobregiro, buscando obtener esos recursos en el mercado de dinero. Esta circunstancia le indicaría al mercado que el Banco de México ha ajustado su postura de política monetaria a restrictiva.

De acuerdo con el cuadro 2.1, desde que inició el régimen de saldos acumulados los "cortos" que se han instrumentado hasta la fecha no representan siquiera el $1 \%$ de la base monetaria. Asimismo, es en los años de 1995 y de 1998 cuando los cambios en el "corto" han sido más frecuentes.

Se han instrumentado algunas medidas adicionales para mejorar el control sobre la cantidad de dinero y las tasas de interés en el régimen. Con el propósito de impedir que las fluctuaciones en los saldos de las cuentas corrientes de los bancos se traduzcan en presiones al alza sobre las tasas de interés en el último día del periodo de medición o en los días previos a éste, se han establecido límites al saldo positivo diario que computa para el cálculo del saldo acumulado de cada institución. Estos límites impiden que los bancos que han acumulado saldos negativos considerables a lo largo de un periodo compensen éstos al final del periodo mediante depósitos por igual monto en el Banco Central. Los límites al saldo positivo diario también establecen un tope al tamaño del saldo acumulado negativo que un banco puede compensar en función del número de días que le faltan al periodo de cálculo.

\footnotetext{
${ }^{3}$ Es importante puntualizar que las señales de política monetaria que envía el Banco de México deben inferirse del anuncio de su objetivo de saldos acumulados y no del saldo acumulado observado con posterioridad. Esto, debido a que las intenciones del Banco están incorporadas en el primero de ellos. En contraste, el segundo puede diferir del objetivo señalado por el Banco Central por diferentes razones fuera de su control.
} 


\section{Cuadro 2.1 El saldo objetivo anunciado como porcentaje}

de la base monetaria, 1995-2000

\begin{tabular}{|c|c|c|}
\hline Fecha del anuncio & $\begin{array}{c}\text { Saldo objetivo (millones } \\
\text { de pesos) }\end{array}$ & $\begin{array}{c}\text { Como porcentaje } \\
\text { de la base monetaria }\end{array}$ \\
\hline \multicolumn{3}{|l|}{2000} \\
\hline Enero 18 & -180 & $0.13 \%$ \\
\hline \multicolumn{3}{|l|}{1999} \\
\hline Enero 13 & -160 & $0.13 \%$ \\
\hline \multicolumn{3}{|l|}{1998} \\
\hline Noviembre 30 & -130 & $0.12 \%$ \\
\hline Septiembre 11 & -100 & $0.10 \%$ \\
\hline Agosto 17 & -70 & $0.07 \%$ \\
\hline Agosto 10 & -50 & $0.05 \%$ \\
\hline Junio 25 & -30 & $0.03 \%$ \\
\hline Marzo 11 & -20 & $0.02 \%$ \\
\hline \multicolumn{3}{|l|}{1996} \\
\hline Noviembre 26 & 0 & $0.00 \%$ \\
\hline Octubre 14 & -20 & $0.03 \%$ \\
\hline Agosto 19 & 0 & $0.00 \%$ \\
\hline Agosto 5 & -30 & $0.05 \%$ \\
\hline Junio 21 & -40 & $0.07 \%$ \\
\hline Junio 7 & -30 & $0.05 \%$ \\
\hline Enero 25 & -20 & $0.04 \%$ \\
\hline Enero 23 & -5 & $0.01 \%$ \\
\hline \multicolumn{3}{|l|}{1995} \\
\hline Diciembre 28 & 0 & $0.00 \%$ \\
\hline Diciembre 20 & 25 & $0.04 \%$ \\
\hline Diciembre 14 & 50 & $0.08 \%$ \\
\hline Diciembre 13 & 0 & $0.00 \%$ \\
\hline Diciembre 8 & -5 & $0.01 \%$ \\
\hline Diciembre 4 & 0 & $0.00 \%$ \\
\hline Noviembre 23 & 15 & $0.03 \%$ \\
\hline Noviembre 21 & 25 & $0.05 \%$ \\
\hline Noviembre 17 & 55 & $0.11 \%$ \\
\hline Noviembre 16 & 65 & $0.13 \%$ \\
\hline Noviembre 15 & 75 & $0.15 \%$ \\
\hline Noviembre 13 & -100 & $0.20 \%$ \\
\hline Noviembre 9 & -200 & $0.41 \%$ \\
\hline Octubre 30 & 25 & $0.05 \%$ \\
\hline Julio 25 & 20 & $0.04 \%$ \\
\hline Julio 9 & 25 & $0.05 \%$ \\
\hline
\end{tabular}

También se han fijado límites al sobregiro diario que puede ser compensado. Estos límites se han establecido con el propósito de evitar que los bancos incurran en sobregiros excesivos al inicio del periodo de medición, a fin de presionar a la baja las tasas de interés. Así cuando un sobregiro diario es mayor que su límite, el exceso ya no puede ser compensado y el banco en cuestión debe pagar dos veces la tasa de interés de mercado por el monto del excedente. Sin embargo, dicho 
monto excedente no es computable para el cálculo del saldo acumulado de ese banco y por tanto no tiene que ser compensado con saldos positivos. Ambos límites, tanto los fijados para los saldos positivos como para los negativos, se determinan caso por caso, en función del pasivo o del capital de cada institución. ${ }^{4,5}$

Otro factor que puede afectar la respuesta al "corto" es la posición relativa de los participantes con respecto al Banco de México en el mercado de dinero. Una posición acreedora del Instituto Central con respecto al mercado de dinero significa que el mercado, por lo general, inicia el día con un faltante de liquidez. En estas circunstancias, el Banco de México tiene que ofrecer los recursos necesarios la mayoría de los días mediante subasta, lo cual significa que aquellos participantes que ofrecen las mayores tasas de interés son los que obtienen los fondos. Esto introduce un sesgo al alza de las tasas de interés que mejora la efectividad del "corto" como medida restrictiva. En contraste, una posición deudora significa que, por lo general, al inicio de la sesión diaria del mercado de dinero existe un exceso de liquidez que obliga al Banco de México a retirar los recursos excedentes mediante subastas de depósitos. En dichas subastas las instituciones de crédito que ofrecen las menores tasas de interés son las que entregan dichos recursos al Banco de México. Esta situación sesga a la baja a las tasas de interés, lo cual podría hacer más difícil inducir incrementos en las tasas de interés mediante el uso de "cortos".

En México se observa que desde principios de 1997, la postura del Banco de México en el mercado de dinero pasó de acreedora a deudora, debido fundamentalmente a la gran acumulación de activos internacionales durante el año. Así, para fortalecer el efecto del "corto" en dos ocasiones, septiembre de 1998 y febrero de 1999, el Banco de México obligó a las instituciones de crédito a constituir depósitos en el Instituto Central por 25,000 millones de pesos a un plazo indefinido. Estos depósitos devengan una tasa de interés equivalente a la $\operatorname{TIIE}^{7}$ a 28 días y se distribuyen entre las instituciones de crédito con base en los pasivos totales de los bancos a cierta fecha de cierre. Sin embargo, acto seguido el Banco de México repone toda la liquidez que llega a retirar por virtud de la constitución de los mencionados depósitos mediante operaciones de mercado abierto a muy corto plazo. De esta manera, el Banco de México se mueve en la dirección de lograr una posición acreedora en el mercado de dinero, a fin de obtener un mayor control sobre la evolución de las tasas de interés de corto plazo. ${ }^{8}$

\footnotetext{
${ }^{4}$ Informe Anual del Banco de México 1996, Banco de México.

${ }^{5}$ Actualmente, los límites a saldos positivos y sobregiros en las cuentas de las instituciones bancarias para cada institución se fijan de acuerdo a la siguiente fórmula: Límite=Min\{230 millones de pesos, Max\{0.25\% Pasivo, 7.5\% Capital\}\}. Esta fórmula tiene la virtud de que los bancos pequeños no están sujetos a una regla de pasivos o de capital que por su tamaño los podría situar en desventaja para utilizar sus cuentas en el Instituto Central.

${ }^{6}$ Una explicación más detallada de las razones por las cuales es importante para un banco central contar con la existencia de una demanda por liquidez por parte de la banca puede encontrarse en Schwartz (1998).

${ }^{7}$ Por sus siglas, Tasa de Interés Interbancaria de Equilibrio.

${ }^{8}$ Informe Anual 1998 e Informe sobre el primer semestre de 1999, Banco de México.
} 


\section{Análisis de los efectos sobre la tasa de interés de fondeo}

\subsection{Descripción de los Datos}

Para este análisis contamos con datos diarios del periodo del 7 de septiembre de 1995, fecha en que se estableció el régimen de saldos acumulados, al 31 de enero de 2000 de las siguientes variables: tasa de fondeo, objetivo de saldos acumulados, tipo de cambio de venta al cierre, ${ }^{9}$ tasa de interés del bono del tesoro de Estados Unidos a 30 años, índices de las bolsas de valores de Rusia y Brasil y el diferencial (spread) soberano del bono Brady de México a descuento (gráficas 3.1 a 3.7). Las tres primeras variables provienen del sistema de información económica del Banco de México, la tasa de interés del bono a 30 años del Federal Reserve Economic Data y las demás variables de Bloomberg. Los índices de las diferentes bolsas de valores corresponden a observaciones diarias del nivel de cierre expresado en dólares. Asimismo, para tener una escala más homogénea trabajamos con el logaritmo natural de estos índices. El diferencial de tasas del bono Brady de México a descuento es la diferencia en rendimientos del Bono Brady y del bono del Tesoro de Estados Unidos a 30 años. ${ }^{10}$

Conviene destacar que la relación inversa entre la tasa de fondeo y el objetivo de saldos acumulados y la relación directa entre la tasa de fondeo y el tipo de cambio pueden apreciarse a simple vista. Sin embargo, la relación con las demás variables no es evidente. Tampoco se puede deducir de las gráficas el sentido de la causalidad entre las variables en cuestión, por lo que se plantea un modelo lineal de determinación de las tasas de interés que se basa en supuestos sobre el sentido de la causalidad entre ellas consistentes con la teoría económica. Esta teoría es menos precisa en cuanto a la relación entre la tasa de interés y el tipo de cambio, por lo que sobre ésta se realizan pruebas adicionales en la sección 3.4.

\section{Gráfica 3.1 Tasa de fondeo}

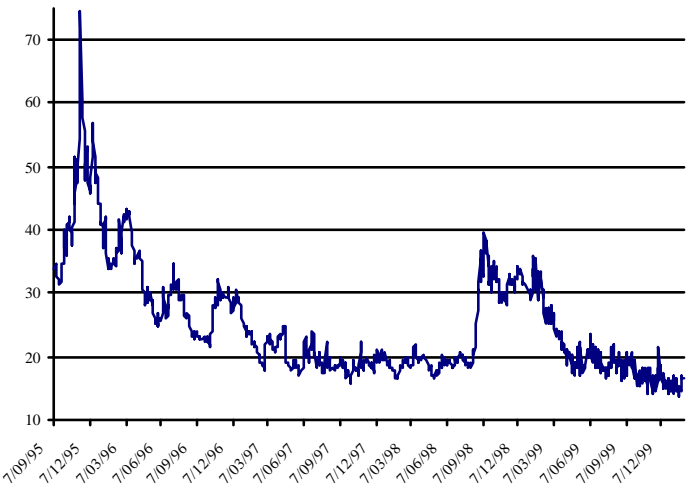

Gráfica 3.2 Saldo acumulado objetivo (millones de pesos)

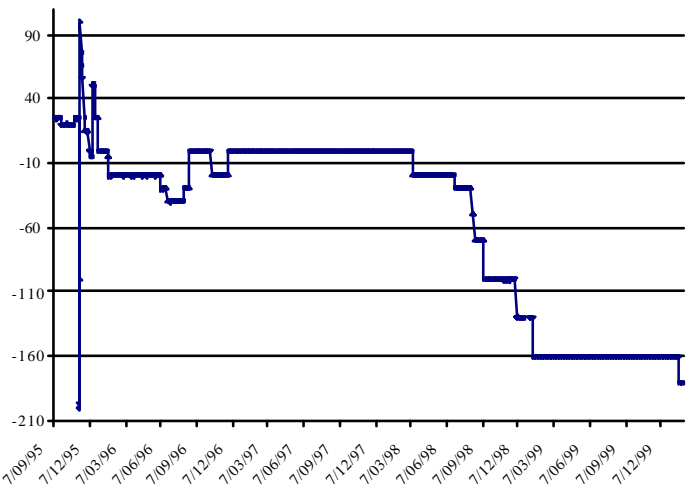

\footnotetext{
${ }^{9}$ Aunque en la selección de algunas variables, como la del tipo de cambio, hay consideraciones de si el mercado está abierto o cerrado y si, por tanto, se debe observar o no un efecto asociado a esta variable, los resultados son robustos si se utiliza la cotización de apertura, la máxima o la mínima.

${ }^{10}$ Otras variables para medir el efecto del riesgo país como el Emerging Market Bond Index, el Latin Eurobond Index (LEI) y el Government Bond Index Plus (GBI+) que publica JP Morgan no funcionaron mejor que la variable de diferencial de tasas que finalmente escogimos para este análisis.
} 
Gráfica 3.3 Tipo de cambio

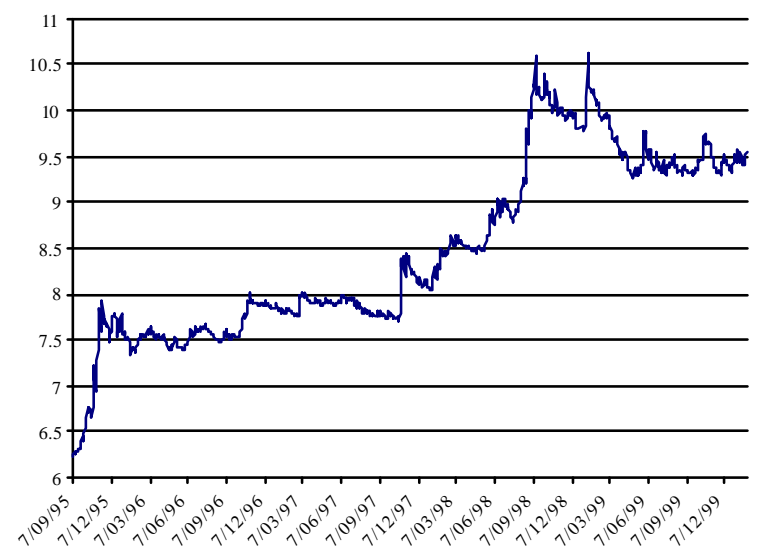

Gráfica 3.5 Índice de la bolsa de valores de Brasil (logaritmo natural)

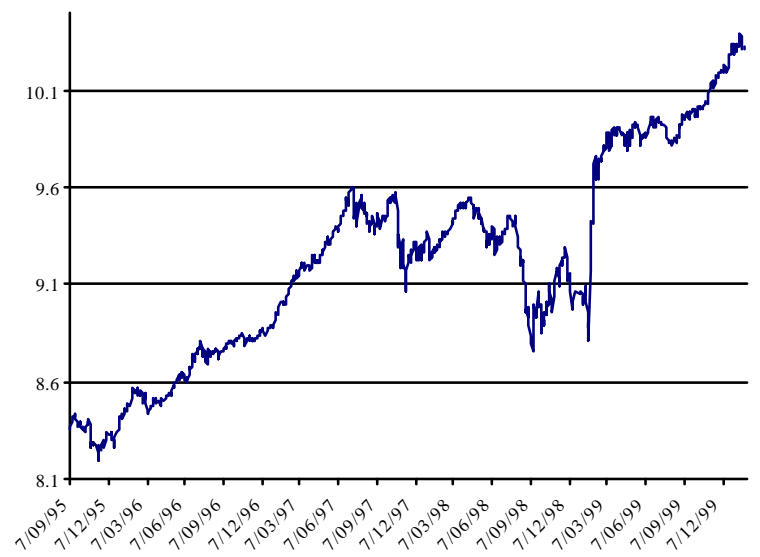

Gráfica 3.4 Diferencia de tasas del bono Brady

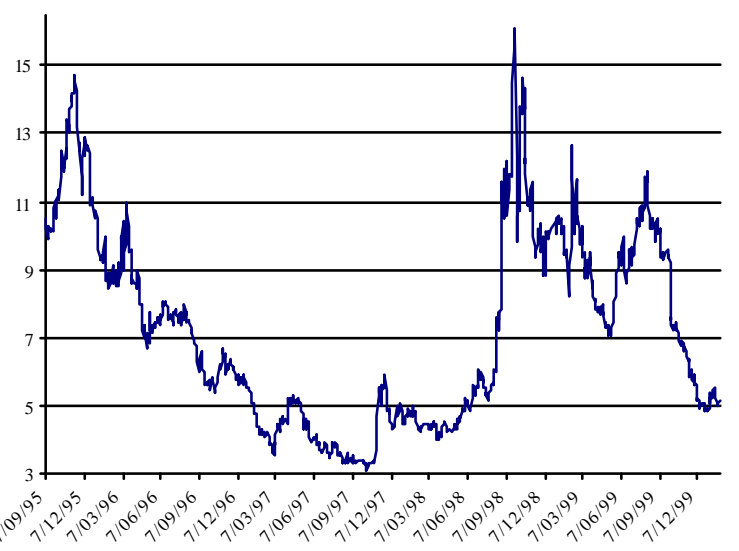

Gráfica 3.6 Índice de la bolsa de valores de Rusia (logaritmo natural)

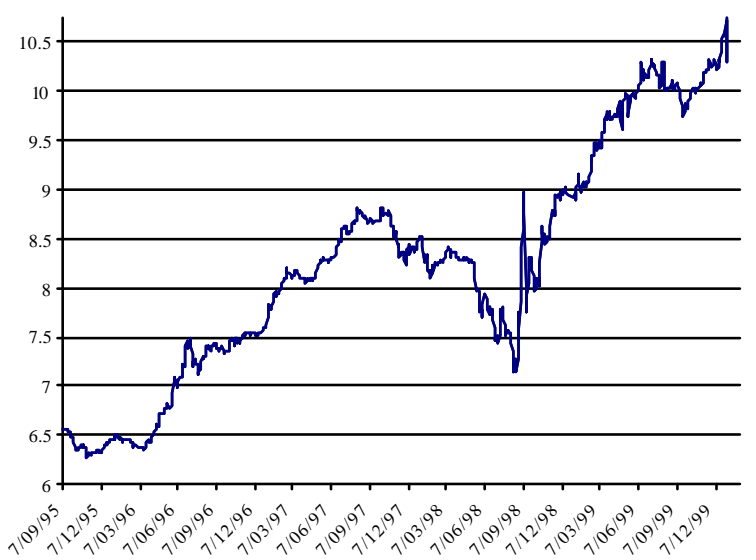

Gráfica 3.7 Tasa de interés del bono del tesoro a 30 años de EEUU

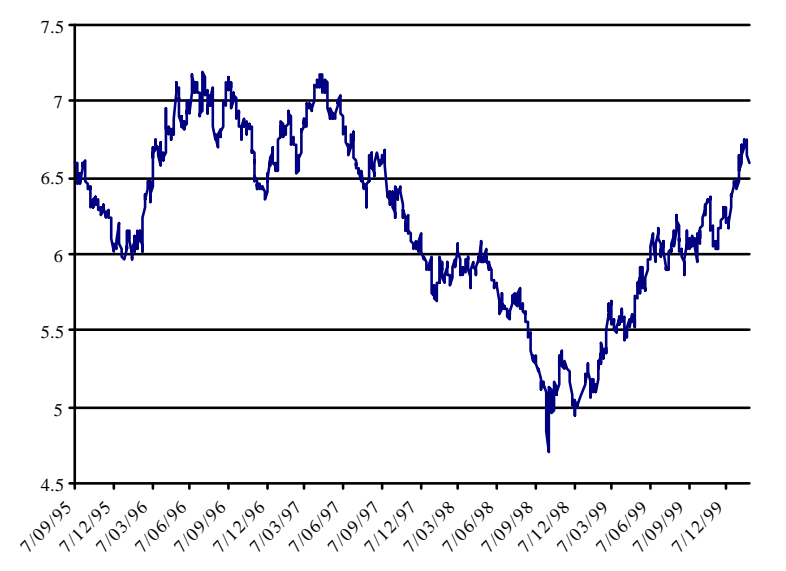


La inspección visual de las gráficas 3.1 a 3.7 también sugiere que las variables en cuestión no son estacionarias en niveles, ${ }^{11}$ lo cual comprobamos mediante las pruebas de Dickey-Fuller. Debido a que en primeras diferencias las variables son estacionarias al 1\%, el análisis econométrico se realiza tomando en cuenta este resultado (cuadro 3.1).

\section{Cuadro 3.1 Prueba de Dickey Fuller Aumentada}

(Primeras diferencias)

\begin{tabular}{lr}
\hline \multicolumn{1}{c}{ Variable } & Estadístico de la prueba ADF \\
\hline Tasa de Fondeo & $-15.42073^{*}$ \\
Saldo Objetivo & $-22.53254^{*}$ \\
Tipo de cambio & $-13.36737^{*}$ \\
Bono 30 años & $-15.55539^{*}$ \\
Indice de la Bolsa de Valores de Brasil & $-15.70576^{*}$ \\
Indice de la Bolsa de Valores de Rusia & $-16.62339^{*}$ \\
Diferencia de tasas del Bono Brady de México & $-15.87859^{*}$ \\
\hline
\end{tabular}

"Significativo al $1 \%,{ }^{* *}$ Significativo al $5 \%,{ }^{* * *}$ Significativo al $10 \%$.

Finalmente, una última característica importante de los datos (especialmente evidente en las gráficas 3.1, 3.3 y 3.4) es que la volatilidad de las series no es constante. Esta es una característica estilizada de series financieras con periodicidad diaria que examinaremos con mayor detalle en la siguiente sección.

\subsection{Modelo Lineal Simple}

El modelo más simple de determinación de tasas de interés consiste en una especificación lineal estimable a través de mínimos cuadrados ordinarios (MCO) de la tasa de fondeo con respecto al objetivo de saldos acumulados, el tipo de cambio y una serie de rezagos de cada una de estas variables, cuyo número óptimo se determina de acuerdo con los criterios de información de Akaike (AIC) o de Schwartz (SBC). ${ }^{12}$ Sin embargo, un análisis preliminar del modelo para el periodo que analizamos revela problemas de autocorrelación y heteroscedasticidad condicional en los residuales, los cuales tratamos de controlar, por una parte, incluyendo algunos rezagos de la tasa de fondeo y, por la otra, incluyendo el diferencial de tasas soberano del bono Brady de México a descuento y los índices de bolsa de algunos países que han enfrentado episodios de volatilidad en el periodo de estudio. ${ }^{13}$ En consecuencia, la ecuación de la tasa de fondeo que estimamos es la siguiente:

\footnotetext{
${ }^{11}$ Los choques a una serie de tiempo estacionaria necesariamente son temporales; a través del tiempo, los efectos de los choques se disipan y las series regresan al nivel de su media de largo plazo. Suponiendo que una serie es generada por un proceso de primer orden $y_{t}=a_{l} y_{t-1}+\varepsilon_{t}$, el hecho de que $\left\{\varepsilon_{t}\right\}$ sea un proceso de ruido blanco y $\left|a_{l}\right|<1$ garantizan que as secuencia $\left\{y_{t}\right\}$ sea estacionaria en niveles (Enders, 1995).

${ }^{12}$ Véase para el caso de México Aguilar y Juan-Ramón (1997) y Greenham (1997) y para el caso de Estados Unidos Fleming y Remolona (1997).

${ }^{13}$ Un supuesto básico en los modelos econométricos convencionales es que la varianza del término de error es constante. Cuando una serie económica muestra periodos de alta volatilidad y periodos de relativa tranquilidad (como ocurre con la tasa de interés de fondeo, de acuerdo con la gráfica 2.1) el supuesto básico de los modelos econométricos convencionales de que la varianza del término de error es constante no es correcto. En tal caso, es apropiado modelar la volatilidad o varianza del término de error. Para tal fin, una opción es
} 


$$
\begin{aligned}
\Delta \text { fondeo }_{t}= & \beta_{0}+\sum_{h=1}^{0} \beta_{h} \Delta \text { fondeo }_{t-h}+\sum_{i=0}^{p} \delta_{i} \Delta \text { sobj }_{t-i}+\sum_{j=0}^{q} \phi_{j} \Delta l t c_{t-j}+\sum_{k=0}^{r} \varphi_{k} \Delta b 30_{t-k}+ \\
& \sum_{n=0}^{v} \gamma_{n} \text { slrusia }_{t-n}+\sum_{\tilde{n}=0}^{w} \eta_{\tilde{n}} \Delta \text { lbrasil }_{t-\tilde{n}}+\sum_{f=0}^{g} \kappa_{f} \Delta \text { spread }_{t-f}+\varepsilon_{t},
\end{aligned}
$$

donde fondeo $_{t}$ es la tasa de interés de fondeo, $\operatorname{sobj}_{t}$ es el saldo acumulado objetivo, ltc $_{t}$ es el logaritmo del tipo de cambio, $b 30_{t}$ es la tasa de interés del bono del tesoro a 30 años de Estados Unidos, lrusia $_{t}$ es el logaritmo del índice de la bolsa de valores en Rusia, lbrasil $t_{t}$ es el logaritmo del índice de la bolsa de valores de Brasil, spread $_{t}$ es el diferencial de tasas soberano del bono Brady de México a descuento y $\varepsilon_{t}$ es término de error en el periodo $t$. Como mencionamos anteriormente, debido a la no estacionariedad en niveles de estos datos utilizamos las primeras diferencias, de manera que $\Delta x_{t}=x_{t}-x_{t-1}{ }^{14}$

A pesar de que el régimen de saldos acumulados se establece en septiembre de 1995, en las estimaciones de esta sección utilizamos sólo datos a partir de febrero de 1996. Durante los meses que se excluyen se observan fluctuaciones erráticas en el "corto" que en alguna medida obedecen más a ajustes en el uso del instrumento que a una intención de modificar las condiciones monetarias por parte de la autoridad en la magnitud observada.

También cabe mencionar que, debido a que encontramos una correlación cercana al 30\% entre el tipo de cambio y la tasa de interés de fondeo, lo cual podría indicar que estas variables se determinan simultáneamente, estimamos la ecuación propuesta con y sin la tasa de depreciación cambiaria corriente. ${ }^{15}$ Por otra parte, para explorar esta posibilidad de causalidad cruzada entre la tasa de interés de fondeo y el tipo de cambio y para corroborar las predicciones de la ecuación 1 realizamos pruebas de causalidad de Granger y estimamos un modelo de vectores autorregresivos con estas variables y el objetivo de saldos acumulados anunciado en la sección 3.4. Los resultados referentes a la causalidad cruzada, mediante pruebas de Granger, sugieren que el tipo de cambio causa en el sentido de Granger a la tasa de interés y no viceversa, lo cual es

introducir explícitamente en el modelo variables independientes para considerar la volatilidad, lo cual puede tener como inconveniente que no existan razones económicas firmes para seleccionar una variable independiente específica sobre otras candidatas (Enders, 1995).

${ }^{14}$ Wasserfallen y Kürsteiner (1994) plantean un modelo semejante para examinar el comportamiento de las tasas de interés y el tipo de cambio bajo el régimen de objetivos de oferta de dinero en Suiza. Los modelos de expectativas racionales típicamente implican que el crecimiento esperado de la oferta de dinero no tiene consecuencias reales. En consecuencia, sólo las variaciones inesperadas en la oferta de dinero (que en nuestro modelo se captan a través de la variación del objetivo de saldos acumulados) resultan en efectos de liquidez. Asimismo, se supone que los efectos de liquidez no son persistentes, de manera que el ajuste ante tales efectos de liquidez es rápido. Sin embargo, las variaciones no anticipadas en el crecimiento de la oferta monetaria no son directamente observables y el fracaso para identificar correctamente los componentes esperados e inesperados de la oferta monetaria pueden resultar en errores de medición relativos a la hipótesis que se investiga.

${ }^{15}$ Exploramos esta posibilidad mediante la estimación de un modelo de mínimos cuadrados en dos etapas con el tipo de cambio corriente como variable endógena adicional. Los resultados indican que al menos los coeficientes asociados al corto y al spread son bastante robustos. Estas estimaciones están disponibles a petición del lector. 
indicativo de que es apropiado incluir el valor contemporáneo del tipo de cambio en la ecuación 1. Sin embargo, las funciones de impulso respuesta del vector autorregresivo indican que el efecto sobre una de estas variables con respecto a un choque en la otra dependen del orden en que se especifican estas dos variables.

La estimación de la ecuación 1 se presenta en la columna A, incluyendo la tasa de depreciación corriente y B, excluyendo la tasa de depreciación corriente, del cuadro 3.2. Los coeficientes significativamente diferentes de cero a los niveles convencionales de estas dos regresiones difieren poco, excepto en los casos del bono de Estados Unidos, que no es significativo en la regresión A y es positivo y significativo en la regresión B, y del índice de la bolsa de valores de Brasil, de cuya suma de coeficientes significativos se obtiene signo positivo en la regresión A y signo negativo en la regresión B. El coeficiente asociado a la tasa de depreciación corriente es 27.1 puntos porcentuales, por lo que el efecto contemporáneo asociado a un incremento del $1 \%$ en la tasa de depreciación corriente es aproximadamente un incremento de 20 puntos base en la tasa de fondeo.

De acuerdo con la regresión A del cuadro 3.2, los efectos acumulados, considerando que un cambio en la tasa de interés en el periodo $t$ tiende a distribuirse durante los siguientes 15 periodos, son los siguientes: una reducción del saldo objetivo de 20 millones de pesos se asocia a un incremento en la tasa de interés de 150 puntos base, un incremento en la tasa de depreciación de $1 \%$ se asocia a un incremento de 45 puntos base (considerando depreciación corriente y del periodo anterior), un incremento de $1 \%$ del índice de la bolsa de Brasil se asocia a un incremento de 34 puntos base, un incremento de $1 \%$ del índice de la bolsa de Rusia se asocia a un incremento de 142 puntos base y, finalmente, un incremento de $1 \%$ del diferencial de tasas soberano del bono Brady se asocia a un incremento de 24 puntos base. Es útil, para efectos de comparación, hacer referencia al trabajo de Greenham (1997), cuya estimación de MCO para la tasa de fondeo con datos de enero de 1996 a marzo de 1997 reporta un incremento en esa tasa de 187 puntos bases asociado a un corto de 20 millones de pesos y un incremento de 223 puntos base asociado a un aumento de 10 centavos en el tipo de cambio, y al de Aguilar y Juan-Ramón (1997), cuya estimación con la misma metodología con datos de septiembre de 1995 a diciembre de 1996 reporta un incremento en la tasa de fondeo de 144 puntos base asociado a un "corto" de 20 millones de pesos y un incremento de 230 puntos base asociado a una depreciación de 10 centavos. Las pruebas de $R^{2}$ y $R^{2}$ Ajustada de nuestra estimación también tienen valores semejantes a las de Greenham (1997) y Aguilar y Juan-Ramón (1997). ${ }^{16}$

\footnotetext{
${ }^{16}$ En el apéndice presentamos nuestras estimaciones de los modelos de Aguilar y Juan-Ramón (1997) y Greenham (1997).
} 


\subsubsection{Cuadro 3.2 Estimación del Modelo Lineal 01/02/1996 a 31/01/2000}

Variable Dependiente: $\Delta(\text { FONDEO }(t))^{\text {a }}$

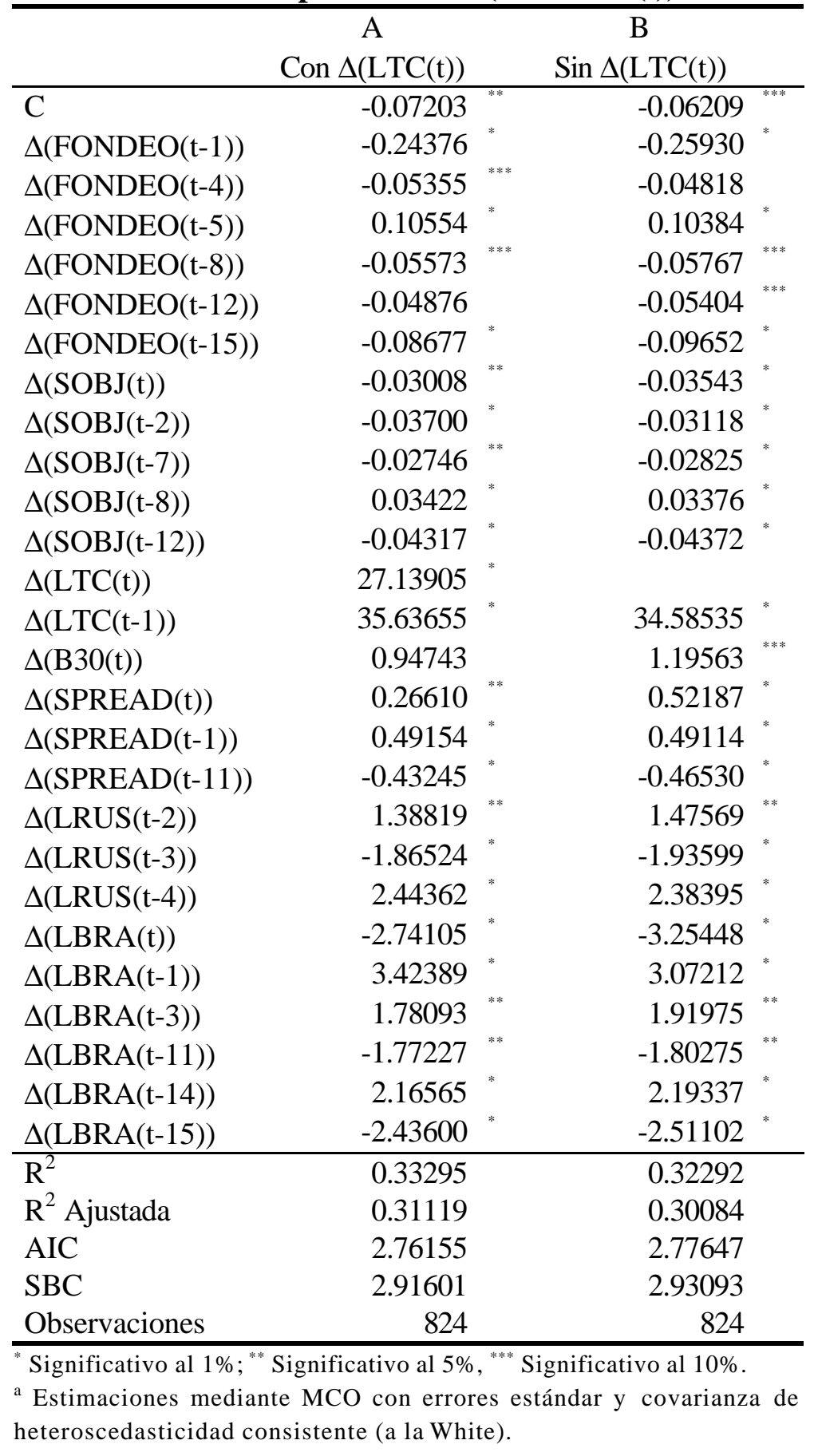

Para las variables asociadas a la volatilidad del entorno internacional no contamos con una referencia semejante. Si bien, por ejemplo, en los informes del Banco de México de 1998 y 1999 se reconoce la importancia de los efectos de contagio sobre la economía mexicana, especialmente sobre los movimientos de las tasas de interés y el tipo de cambio, los coeficientes asociados a los índices de las bolsas de Brasil y Rusia parecen grandes considerando que la alta volatilidad de estas variables ocurre en episodios específicos (gráficas 3.6 y 3.7). También cabe 
mencionar que la magnitud de los coeficientes asociados al spread no cambia mucho si se excluyen las variables asociadas a las bolsas extranjeras, pero la de aquéllos asociados a la depreciación del tipo de cambio si son ligeramente mayores cuando las variables mencionadas se excluyen. ${ }^{17}$

A continuación realizamos pruebas de autocorrelación, de efectos tipo $\mathrm{ARCH}^{18}$ y estabilidad para la regresión A. Las pruebas de autocorrelación de Breusch-Geoffrey LM para los primeros 15 rezagos indican que la hipótesis de cero autocorrelación no se rechaza para los nivel de significancia convencionales del 1 y $5 \%$ (cuadro 3.3). ${ }^{19}$ Por tanto, no hay evidencia que sugiera un movimiento sistemático de la variable dependiente que no está tomado en cuenta en los coeficientes obtenidos de la estimación de mínimos cuadrados ordinarios.

Sin embargo, las pruebas ARCH LM para los primeros 15 rezagos indican que la hipótesis de cero efectos ARCH se rechaza para cualquier nivel de significancia, de manera que persisten estos efectos a pesar de las variables incluidas para controlar por la volatilidad internacional (cuadro 3.4). ${ }^{20}$ La heterocedasticidad en los residuales, al igual que la autocorrelación, invalida las fórmulas convencionales de los errores estándar. Por tanto, los coeficientes obtenidos mediante la estimación de mínimos cuadrados ordinarios son ineficientes y la inferencia basada en éstos es afectada de manera adversa. ${ }^{21,22}$

\footnotetext{
${ }^{17}$ Obsérvese que los resultados de Greenham (1997) y Aguilar y Juan Ramón (1997) reportan efectos asociados a la depreciación del tipo de cambio mayores que los aquí reportamos y no incluyen variables para captar volatilidad internacional.

${ }^{18}$ Por sus siglas en inglés, Autoregressive conditional heteroscedasticity.

${ }^{19}$ La prueba de autocorrelación de Breusch-Godfrey es una prueba de multiplicador de Lagrange de la hipótesis nula de cero autocorrelación, en contraste con la hipótesis alternativa de AR(p) (ó MA(p)), donde p es el número de rezagos de los residuales cuadrados de la regresión. Esta prueba es una prueba conjunta de los primeros $p$ coeficientes de autocorrelación.

${ }^{20} \mathrm{La}$ prueba ARCH LM se basa en una regresión de los residuales cuadrados de un periodo con respecto a una serie de rezagos de los residuales cuadrados. Por ejemplo, si hay 3 rezagos entonces $u_{t}^{2}=\beta_{1}+\beta_{2} u_{t-1}^{2}+$ $\beta_{3} u_{t-2}^{2}+\beta_{4} u_{t-3}^{2}+\ldots$. El producto de esta prueba es un estadístico $\mathrm{F}$, y un estadístico (\# de observaciones) $* R^{2}$, que se distribuye como una $\chi^{2}$, cada uno con un valor de probabilidad relevante para rechazar la hipótesis nula de cero efectos ARCH.

${ }^{21}$ Sin embargo, si la heteroscedasticidad no está correlacionada con las variables del modelo entonces, al menos en muestras grandes, las estimaciones de mínimos cuadrados no están sesgadas, si bien no utilizan los datos de manera óptima (Green, 1993).

${ }^{22}$ En una versión anterior de este documento estimamos un modelo GARCH de la tasa de fondeo utilizando como ecuación de la media condicional la ecuación 1 y como ecuación del proceso de error: $\varepsilon_{t}=v_{t} \sqrt{h_{t}}$, donde $v_{t}$ es un proceso de ruido blanco tal que $\sigma_{v}^{2}=1 \mathrm{y}$

$$
h_{t}=\alpha_{0}+\sum_{i=1}^{q} \alpha_{i} \varepsilon_{t-i}^{2}+\sum_{j=1}^{p} \gamma_{j} h_{t-j}
$$

donde $h_{t}$, la varianza del término de error, depende de los términos de error al cuadrado de $q$ periodos anteriores (o efectos ARCH), $\varepsilon_{t-i}^{2}$, y de las varianzas de $p$ periodos anteriores (o efectos GARCH), $h_{t-j}$. Los resultados de esta estimación indican en la ecuación de la varianza condicional se observa que tanto la constante como los coeficientes asociados a efectos ARCH(1) y GARCH(1) son positivos y significativamente diferentes de cero. No obstante, la comparación de la ecuación de la media condicional del modelo GARCH con la ecuación de MCO indica que los coeficientes de MCO son relativamente robustos tanto en signo como en magnitud en este caso.
} 


\section{Cuadro 3.3 Pruebas de Autocorrelación Breusch-Godfrey LM de la Regresión A}

\begin{tabular}{crr}
\hline Rezagos & Estadístico F & (\# de observaciones)* $\mathrm{R}^{2}$ \\
\hline 1 & 2.05920 & 2.12614 \\
3 & 2.36126 & $7.28642^{* * * * *}$ \\
5 & 1.77556 & 9.13413 \\
7 & 1.59058 & 11.45189 \\
9 & 1.51936 & 14.05507 \\
11 & 1.52504 & 17.21905 \\
13 & 1.33955 & 17.90498 \\
15 & 1.22459 & 18.91130 \\
\hline
\end{tabular}

${ }^{*}$ Significativo al 1\%, ${ }^{* *}$ Significativo al $5 \%,{ }^{* * *}$ Significativo al $10 \%$

\subsubsection{Cuadro 3.4 Pruebas de Heteroscedasticidad Arch LM} de la Regresión A

\begin{tabular}{crr}
\hline Rezagos & Estadístico F & (\# de observaciones)* ${ }^{2}$ \\
\hline 1 & $21.68703^{*}$ & $21.18038^{*}$ \\
3 & $19.53138^{*}$ & $54.94075^{*}$ \\
5 & $15.00186^{*}$ & $69.18014^{*}$ \\
7 & $10.45399^{*}$ & $67.77135^{*}$ \\
9 & $11.33767^{*}$ & $72.98827^{*}$ \\
11 & $9.56104^{*}$ & $94.35790^{*}$ \\
13 & $8.39158^{*}$ & $97.64201^{*}$ \\
15 & $7.26360^{*}$ & $97.72543^{*}$ \\
\hline
\end{tabular}

${ }^{*}$ Significativo al $1 \%,{ }^{* *}$ Significativo al $5 \%,{ }^{* * *}$ Significativo al $10 \%$.

Por otra parte, las pruebas de estabilidad que realizamos muestran resultados poco satisfactorios que sugieren que el modelo no ajusta a los datos durante todo el periodo de análisis. En primer lugar está la prueba de residuales recursivos ${ }^{23}$ que indica que hay inestabilidad en varios periodos a partir de junio de 1998 porque a partir de entonces hay muchos residuales que se encuentran fuera de las bandas de confianza de 5\% (cuadro 3.5.a). Las pruebas de suma acumulada de residuales $C U S U M^{24}$ (cuadro 3.5.b) y suma acumulada de residuales cuadrados CUSUM ${ }^{2}$ (cuadro 3.5.c) tienen resultados mixtos, ya que en la primera de ellas el estadístico de la prueba está dentro del intervalo de confianza. Sin embargo, el estadístico de la segunda prueba está notablemente fuera del intervalo de confianza entre diciembre de 1996 y diciembre de 1998 (obsérvese que hay un cambio notable en la trayectoria del estadístico en junio de 1998).

\footnotetext{
${ }^{23}$ Esta prueba grafica los residuales provenientes de la estimación repetida de la regresión de MCO propuesta en muestras sucesivamente más grandes (agregando cada vez una observación al final de la muestra) y una banda de más y menos dos errores estándar. Los residuales situados afuera de la banda indican inestabilidad en los parámetros de la regresión.

${ }^{24}$ Por su siglas en inglés, Cumulative Sum of the Residuals. Esta prueba se basa en un estadístico que se construye mediante la suma acumulada de los residuales recursivos. Esta suma se grafica a través del tiempo junto con un intervalo de confianza. La prueba encuentra inestabilidad de los parámetros si la suma acumulada se sale del intervalo de confianza.
} 
El resto de las pruebas también indica inestabilidad. Las pruebas de pronóstico de 1-paso ${ }^{25}$ (cuadro 3.5.d) y $\mathrm{N}-\operatorname{pasos}^{26}$ (cuadro 3.5.e) indican varios puntos en la muestra en los que la probabilidad de que la regresión A ajuste tales puntos es menor que 5\%. En la prueba de pronóstico de 1-paso, los puntos en los que la regresión estimada es menos exitosa se concentran hacia el final de la muestra (nuevamente a partir de junio de 1998). La prueba de pronóstico de $\mathrm{N}$ pasos, a su vez, contiene puntos en los que la probabilidad de ajuste es menor que $5 \%$ a partir de diciembre de 1996 y es cero a partir de marzo de 1997.

Finalmente, los coeficientes recursivos estimados de la regresión A se presentan en el cuadro 3.6. En este cuadro se observa que hay una variación significativa en varios de los coeficientes. En particular, de aquéllos asociados al propio rezago de un periodo de la tasa de fondeo, al saldo objetivo anunciado corriente y a sus rezagos, al rezago de un periodo del tipo de cambio y a la tasa de interés del bono de Estados Unidos corriente.

Este problema es una mala noticia. Exploramos sus repercusiones para efectos de la pregunta que nos interesa en la siguiente sección mediante un análisis de regresiones rodantes. Este método nos permite un seguimiento más cercano de la evolución del efecto del "corto" en este periodo, considerando de manera explícita que los parámetros cambian a través del tiempo.

\footnotetext{
${ }^{25}$ Del inglés, One-Step Forecast Test. Esta prueba produce una gráfica de los residuales recursivos y errores estándar, así como de los valores de probabilidad para aquellos puntos de la muestra en que la probabilidad es igual o menor que $15 \%$. Esto permite identificar los periodos en los que la regresión propuesta es menos exitosa.

${ }^{26}$ Del inglés, N-Step Forecast Test. Esta prueba emplea estimaciones recursivas para realizar una secuencia de pruebas de pronóstico de Chow. En contraste con la prueba de pronóstico de Chow, esta prueba automáticamente computa todos los casos factibles de especificación del periodo de pronóstico, comenzando con la muestra más pequeña con que se puede estimar la ecuación propuesta y agregando una observación cada vez.
} 
Cuadro 3.5 Pruebas de estabilidad de los parámetros de la Regresión A

a) Residuales recursivos

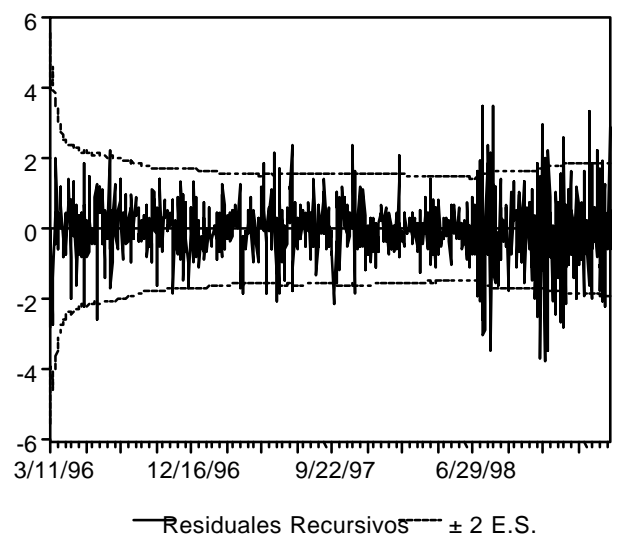

c) CUSUM $^{2}$

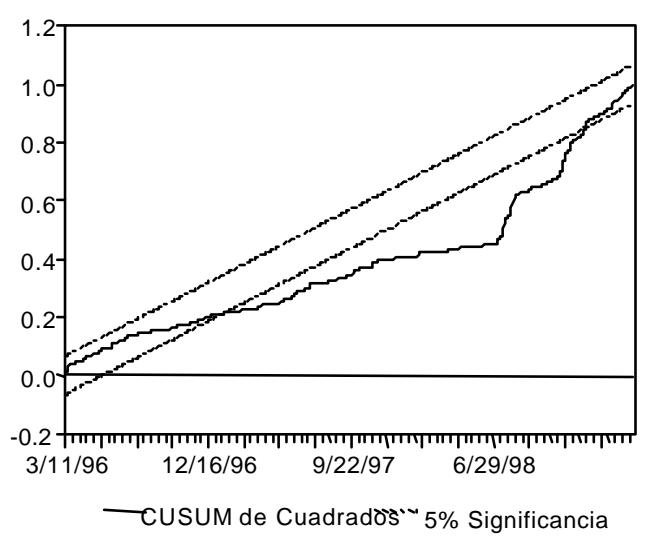

b) CUSUM

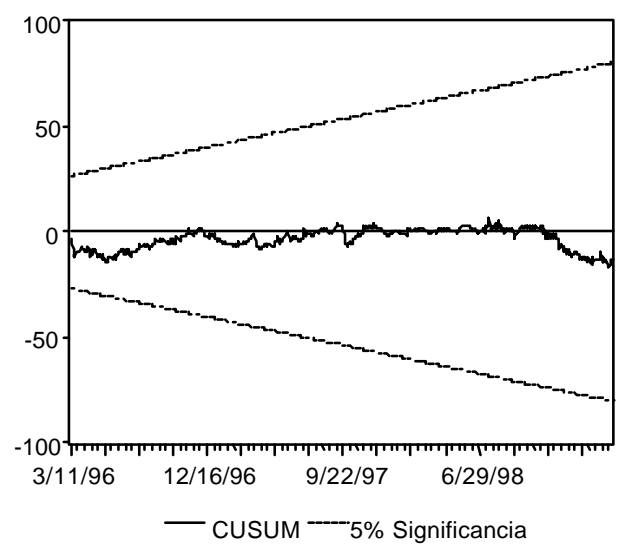

d) Prueba de pronóstico a un paso

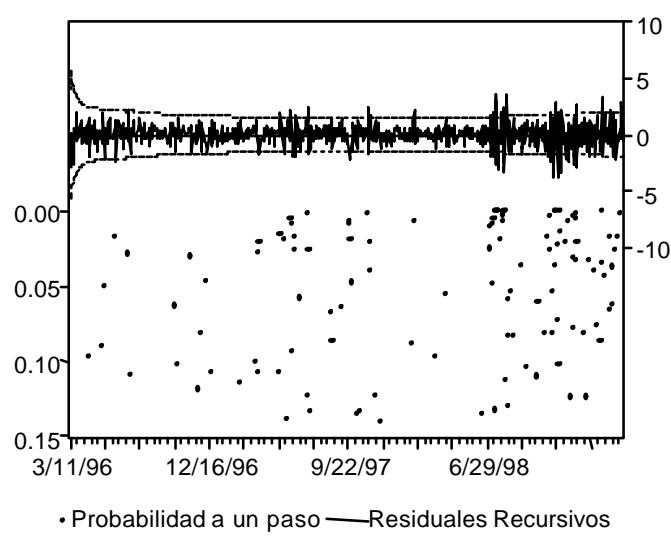

e) Prueba de pronóstico a un paso

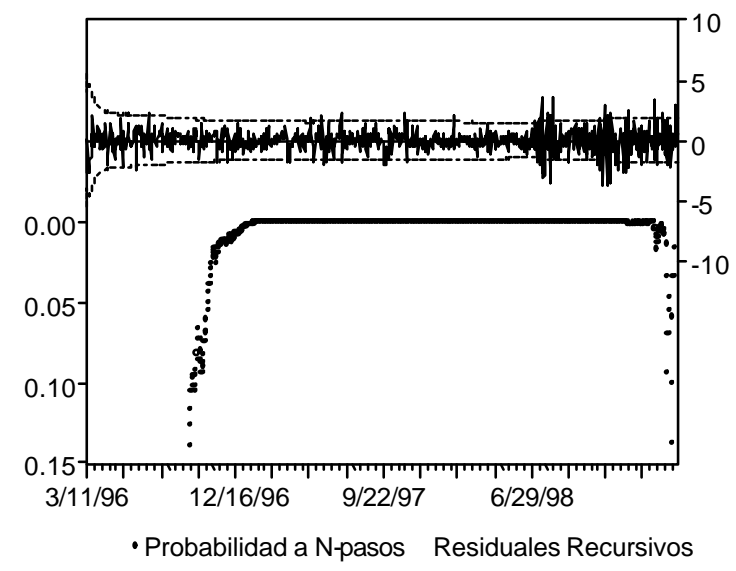




\section{Cuadro 3.6 Prueba de Estabilidad de Coeficientes}

Recursivos Estimados de la Regresión A
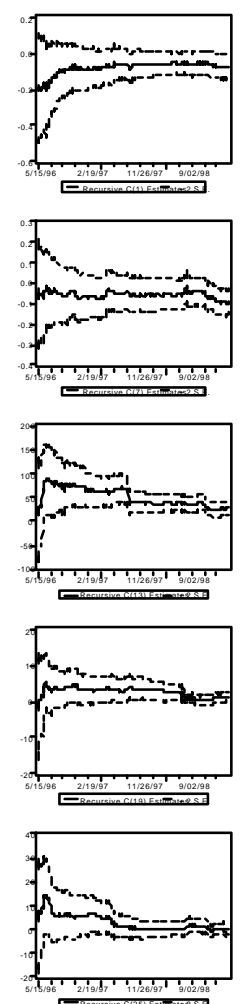
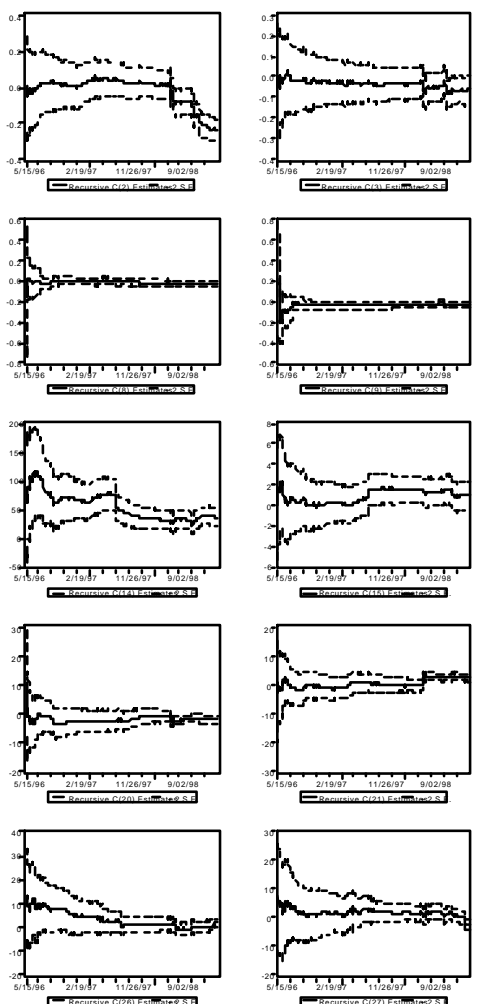
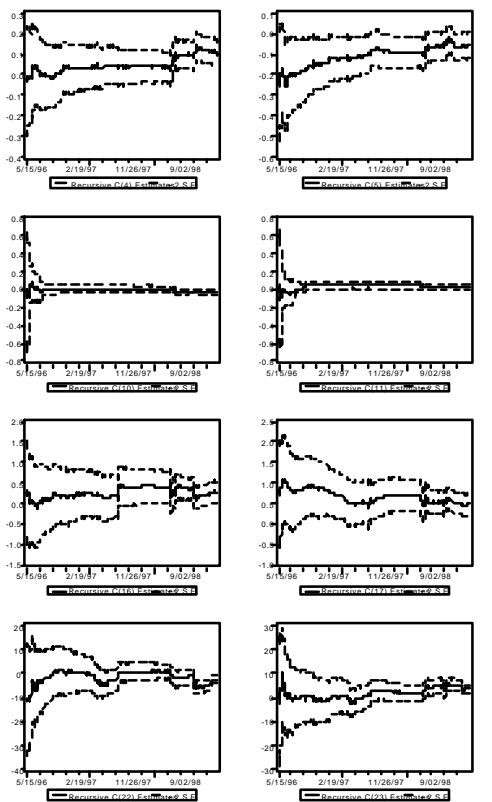
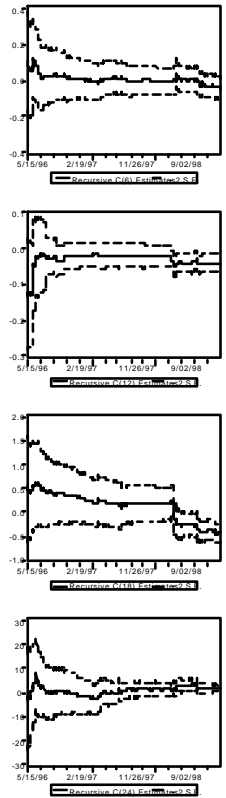


\subsection{Regresiones Rodantes}

Para este ejercicio, inicialmente estimamos la ecuación 1, considerando 6 rezagos de cada variable, para las 500 observaciones del periodo comprendido entre el 1 de febrero de 1996 y el 2 de febrero de 1998 y verificamos que la regresión obtenida cumpliera con la batería de pruebas de autocorrelación, heteroscedasticidad y estabilidad. Denominamos a esta estimación regresión C. Los coeficientes significativos resultantes de la regresión $\mathrm{C}$ se presentan en el cuadro 3.7 y las pruebas de autocorrelación, heteroscedasticidad y estabilidad en el apéndice (cuadros A.3-A.6).

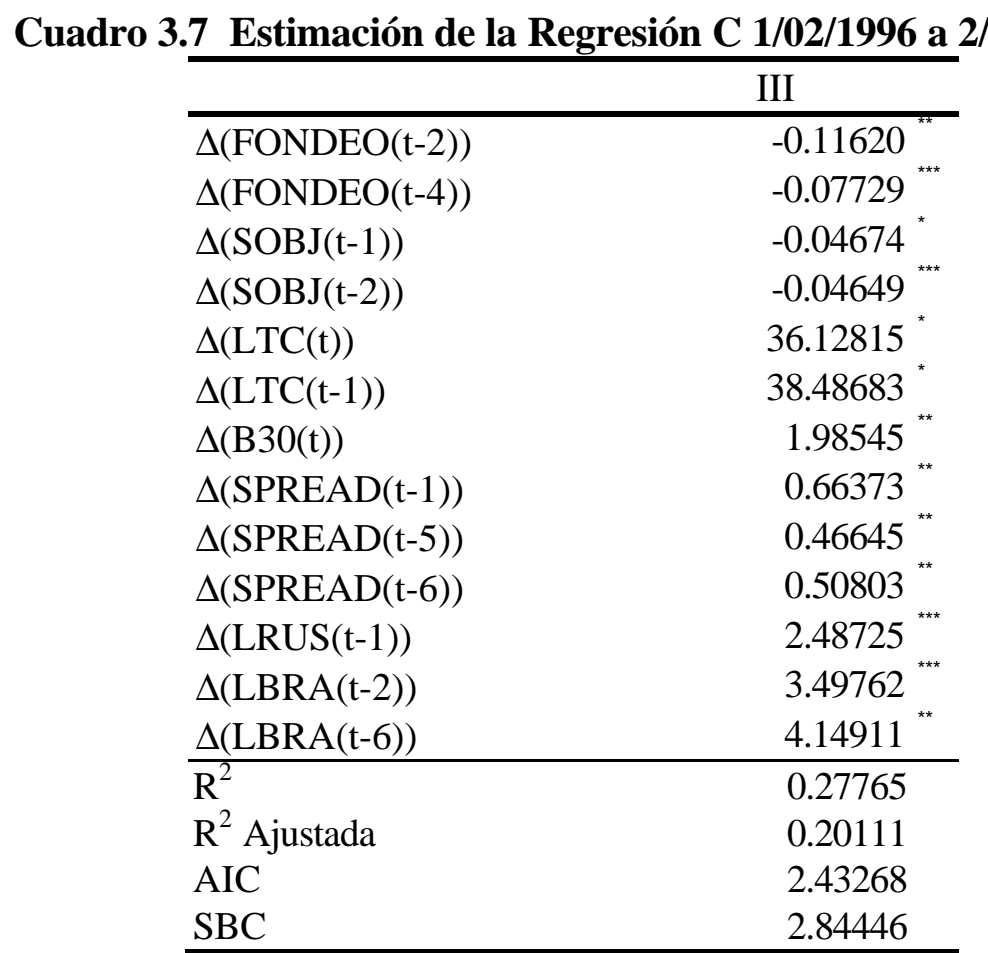

${ }^{*}$ Significativo al $1 \%,{ }^{* *}$ Significativo al $5 \%$,

*** Significativo al $10 \%$.

${ }^{a}$ Estimaciones mediante MCO con errores estándar y covarianza de heteroscedasticidad consistente (a la

White).

En cuanto a los coeficientes de la regresión $\mathrm{C}$, cabe mencionar que los incrementos en la tasa de fondeo asociados a un cambio en el saldo objetivo de un millón de pesos, una depreciación del tipo de cambio de $1 \%$, un aumento de $1 \%$ en la tasa de interés de Estados Unidos y un aumento de $1 \%$ en el diferencial de tasas soberano del bono Brady son de $\quad-0.039,62.5,1.66$ y 1.76 puntos porcentuales, respectivamente. Estas magnitudes difieren notablemente de las que se obtienen utilizando la muestra de datos completa y en el caso del tipo de cambio y la tasa de interés de Estados Unidos éstas coinciden más con Greenham (1997) y Aguilar y Juan-Ramón (1997). En cuanto a las pruebas que aplicamos a la regresión C, sólo mencionaremos aquí que éstas indican que esta regresión no presenta efectos de autocorrelación claramente significativos 
hasta el rezago 15 o problemas notables de estabilidad, pero si de heteroscedasticidad tipo $\mathrm{ARCH} .{ }^{27}$

Proseguimos con la estimación final de esta ecuación desplazando la muestra en una observación hacia adelante cada vez (quitando la observación del principio y agregando una observación para mantener el tamaño de la muestra), obteniendo así 500 estimaciones sucesivas de la regresión C. Las gráficas 3.8 a 3.13 presentan el efecto total de largo plazo sobre la tasa de fondeo asociado a cada variable independiente, computado en cada ecuación como la suma de coeficientes significativos al $1 \%$ y $5 \%$ de tal variable entre la suma de coeficientes significativos al $1 \%$ y $5 \%$ de la tasa de fondeo y sus rezagos.

La gráfica 3.8 presenta el efecto total de largo plazo sobre la tasa de fondeo asociado a un cambio de un millón de pesos en el saldo objetivo anunciado. En congruencia con los resultados de la sección previa, si bien el signo del efecto siempre es negativo o cero, la magnitud del mismo fluctúa. Su promedio es -0.027 puntos porcentuales y tiene una desviación estándar de 0.02 puntos porcentuales. El efecto alcanza su magnitud máxima de -0.088 puntos porcentuales en las regresiones que incluyen los datos inmediatamente anteriores a septiembre de 1998 y su magnitud mínima de cero en prácticamente todas las regresiones que incluyen observaciones del periodo entre septiembre de 1998 y enero de 1999.

\section{Gráfica 3.8 Efecto sobre la tasa de fondeo asociado al saldo objetivo acumulado}

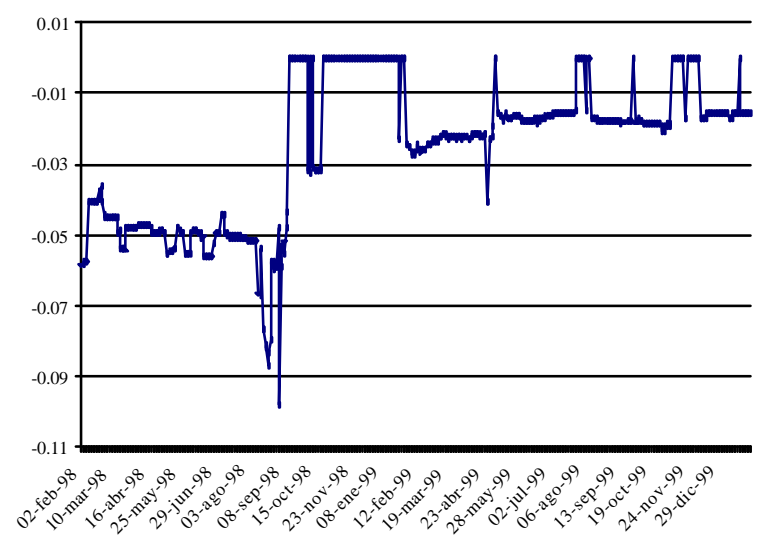

Gráfica 3.9 Efecto sobre la tasa de fondeo asociado a la depreciación del tipo de cambio

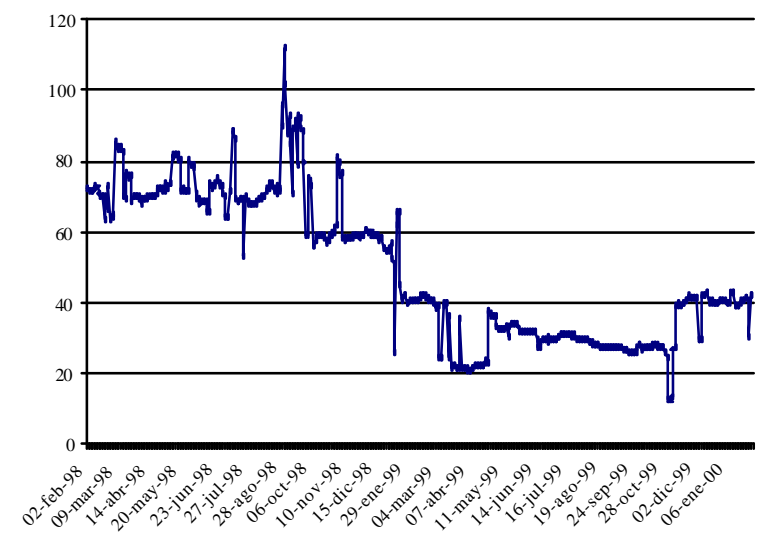

Otro aspecto interesante de la gráfica 3.8 es que puede apreciarse una diferencia notable del efecto promedio asociado al "corto" si se excluyen las observaciones del periodo de septiembre de 1998 a enero de 1999. Antes de ese periodo el efecto promedio de un incremento en el saldo objetivo de un millón de pesos es -0.053 puntos porcentuales y después de ese periodo es 0.020 puntos porcentuales. Por tanto, mientras que antes de la crisis financiera internacional un

\footnotetext{
${ }^{27}$ Obsérvese que las estimaciones de Greenham (1997) y Aguilar y Juan-Ramón (1997) emplean precisamente los datos del periodo en que MCO genera coeficientes más estables. Cabe agregar que nuestras estimaciones del modelo de Greenham (1997) sugieren que éste no tiene alguno de los problemas que mencionamos.
} 
"corto" de 20 millones de pesos producirá un incremento de 106 puntos base, actualmente produce un incremento promedio de 40 puntos base.

El efecto sobre la tasa de fondeo asociado a una depreciación del tipo de cambio de $1 \%$ tiene una magnitud promedio de 48.3 puntos base, una desviación estándar de 19.6 puntos base, un máximo de 105.2 puntos base y un mínimo de 13.5 puntos base. El efecto promedio a partir de febrero de 1998 es, por tanto, menor que entre febrero de 1996 y febrero de 1998 según reportamos anteriormente. De acuerdo con la gráfica 3.9, este efecto es más estable que el del "corto", pero exhibe una tendencia decreciente: entre febrero y diciembre de 1998 el incremento promedio de la tasa de fondeo ante una depreciación de $1 \%$ es aproximadamente 70 puntos base y a partir de enero de 1999 el incremento promedio es aproximadamente 33 puntos base.

Los estadísticos descriptivos del efecto asociado a un incremento del diferencial de tasas del bono Brady de 100 puntos base indican una magnitud promedio de 50 puntos base, una desviación estándar de 36 puntos base, una magnitud máxima de 190 puntos base y una magnitud mínima de 0. Por tanto, nuevamente se observa que el efecto promedio es menor a partir de febrero de 1998 que entre febrero de 1996 y febrero de 1998. Al igual que en el caso del "corto", hay una fluctuación notable en este efecto entre septiembre de 1998 y enero de 1999. A partir de entonces el efecto promedio es más estable: la tasa de fondeo aumenta en 40 puntos base en respuesta a un incremento de 100 puntos base en el diferencial de tasas del bono Brady.

\section{Gráfica 3.10 Efecto sobre la tasa de fondeo Gráfica 3.11 Efecto sobre la tasa de fondeo asociado al diferencial de tasas del bono Brady asociado al índice de la bolsa de valores de Rusia}
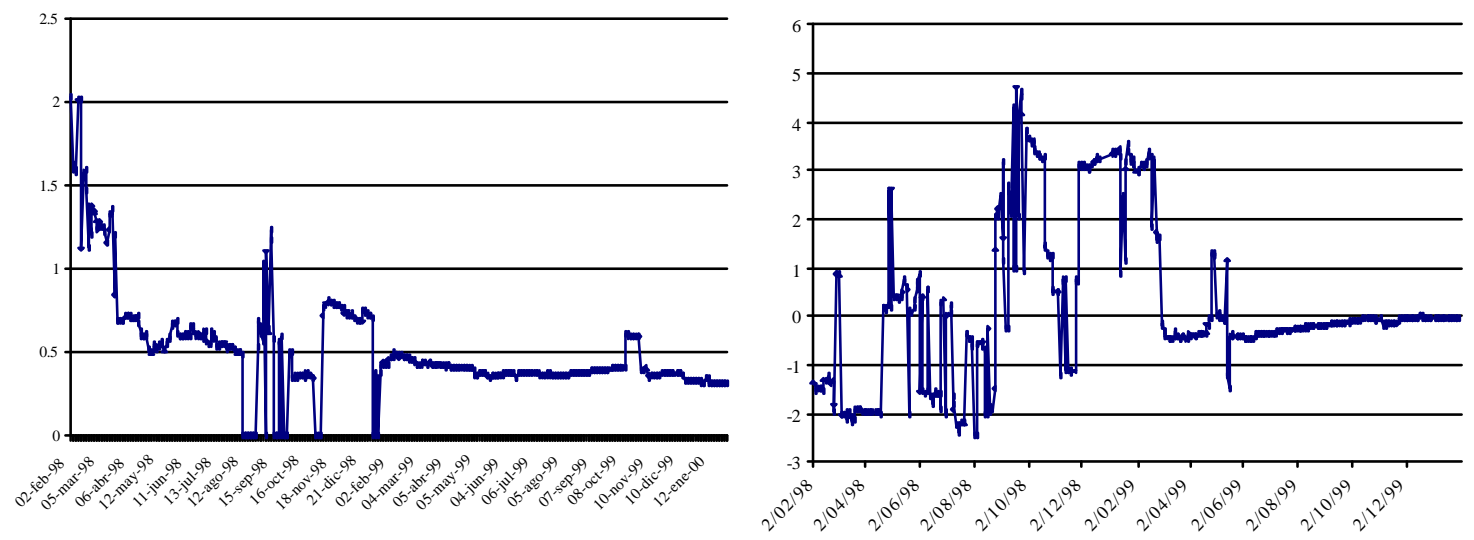

Por último, están los efectos asociados a los índices de las bolsas de valores de Rusia y de Brasil y a la tasa de interés del bono de Estados Unidos a 30 años. Con respecto a los índices de las bolsas de valores de Rusia y Brasil, se observa que en respuesta a un incremento de un punto porcentual de éstos se producen incrementos en la tasa de fondeo de 5.6 y 13.4 puntos porcentuales respectivamente entre septiembre y diciembre de 1998, que es cuando estas variables producen su efecto máximo. Después de ese episodio el efecto de cada una de estas variables se reduce a cero, magnitud que prácticamente se mantiene estable hasta el final de la muestra (gráficas 3.11 y 3.12). Finalmente, el efecto sobre la tasa de fondeo asociado a un 
incremento de un punto porcentual en la tasa de interés de Estados Unidos que se detecta a partir de marzo de 1998 es cero, en contraste con el efecto positivo que se obtiene en la regresión C, de aproximadamente 1.66 puntos porcentuales, y en los dos estudios ya mencionados que también utilizan datos de 1996 y 1997. Una posible explicación de este resultado es que el aumento en la aversión al riesgo y en la preferencia por la liquidez que se dio durante la crisis financiera internacional de 1998 hizo que se redujera la correlación positiva que normalmente existe entre la tasa de fondeo y la tasa del bono de Estados Unidos a 30 años (gráfica 3.13).

Gráfica 3.12 Efecto sobre la tasa de fondeo asociado al índice de la bolsa de valores de Brasil

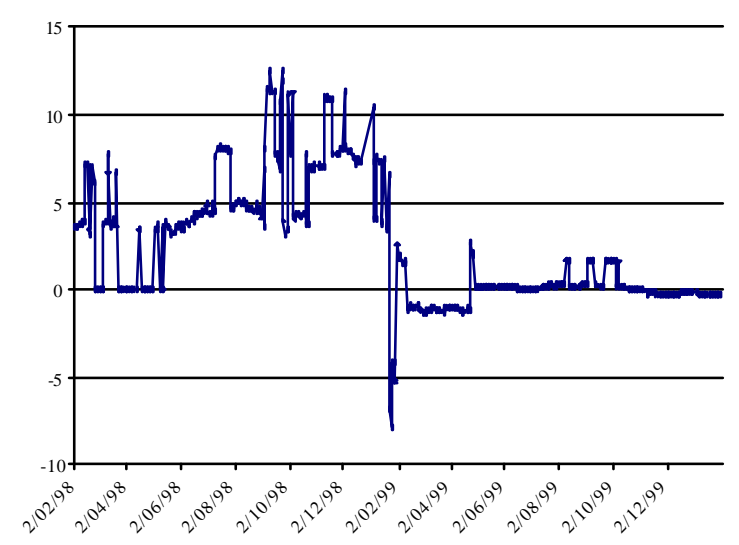

Gráfica 3.13 Efecto sobre la tasa de fondeo asociado a la tasa de interés del bono del Tesoro de EEUU a 30 años

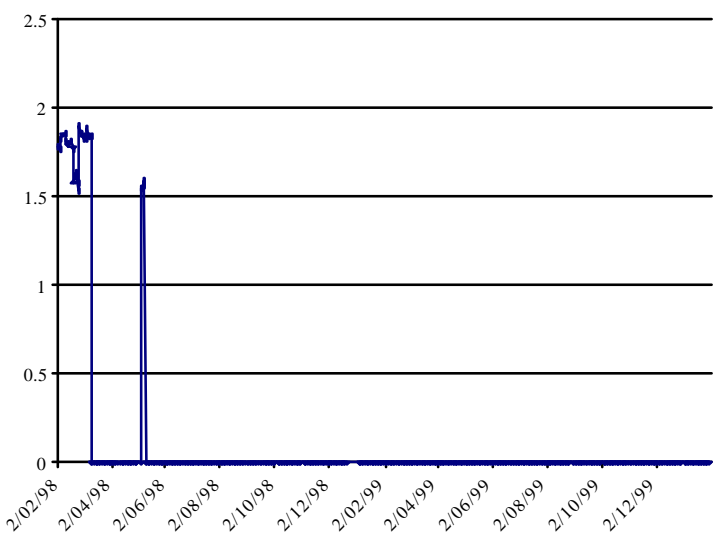

Probablemente el aspecto que más conviene resaltar es que a través de este análisis no sólo se pueden identificar los episodios de inestabilidad de los coeficientes sino que puede medirse el cambio en los coeficientes. La magnitud del efecto del "corto" que se obtiene mediante las regresiones rodantes es, en promedio, notablemente menor que la que encontramos en la sección 3.2 y la que encuentran los otros estudios sobre este tema que emplean MCO. Además, este efecto es aún menor, pero estable, si sólo se consideran los datos posteriores a la crisis financiera internacional de 1998. La inestabilidad de los coeficientes pudiera deberse a un cambio brusco o desproporcional en alguna de las variables de la regresión u otras que no captamos por la crisis financiera internacional. Por tanto, los efectos del "corto" estimados en esta sección son más confiables.

\subsection{Interacción entre la Tasa de Interés de Fondeo, el Tipo de Cambio y el Saldo Objetivo Anunciado}

Como mencionamos en la sección 3.3.1, debido a la posibilidad de que la tasa de interés de fondeo y el tipo de cambio se determinen en forma simultánea probablemente en respuesta a un mismo choque estimamos la ecuación 1 incluyendo y excluyendo de ella el valor corriente de esta variable. En esta sección exploramos con más profundidad la interacción entre la tasa de interés de fondeo, el tipo de cambio y el saldo objetivo anunciado a través del examen de la matriz de correlación, de las pruebas de causalidad de Granger y de un vector autorregresivo (VAR) con estas tres variables. 
De acuerdo con la matriz de correlación presentada en el cuadro 3.8, hay una correlación positiva entre los valores corrientes de estas tres variables. Con todo, mientras que la correlación entre la tasa de interés y el saldo objetivo y entre el tipo de cambio y el saldo objetivo son menores que $10 \%$, aquélla entre la tasa de interés y el tipo de cambio es notablemente más alta, cercana a $25 \%$. Pero cabe recordar que mayor correlación no implica causalidad en ningún sentido de la palabra.

\section{Cuadro 3.8 Matriz de Correlación} (primeras diferencias)

\begin{tabular}{lccc}
\hline & $\begin{array}{c}\text { TASA DE } \\
\text { INTERÉS }\end{array}$ & $\begin{array}{c}\text { TIPO DE } \\
\text { CAMBIO }\end{array}$ & SALDO OBJETIVO \\
\hline TASA DE INTERÉS & 1.0000 & 0.2441 & 0.0731 \\
TIPO DE CAMBIO & 0.2441 & 1.0000 & 0.0912 \\
SALDO OBJETIVO & 0.0731 & 0.0912 & 1.0000 \\
\hline
\end{tabular}

Por consiguiente, estimamos el correlograma cruzado entre la tasa de fondeo y el tipo de cambio con 36 rezagos, el cual indica que la correlación de la tasa de interés corriente con el tipo de cambio correspondiente al periodo inmediato anterior e inmediato posterior es mayor que $25 \%$, en tanto que la correlación de la tasa de interés con el tipo de cambio de 2 periodos antes es casi $20 \%$ pero con el tipo de cambio de 2 periodos después es menor que $3 \%{ }^{28}$ Esta evidencia sugiere cierta causalidad del tipo de cambio hacia la tasa de interés pero no viceversa.

Para corroborar este resultado, se estimaron pruebas de causalidad de Granger con 15 rezagos (cuadro 3.9). La hipótesis de que todos los coeficientes de los rezagos son cero (es decir, que éstos no contribuyen en la predicción de la variable dependiente) se rechaza con niveles de significancia mínimos, excepto para la prueba de causalidad de los coeficientes de la tasa de interés en la ecuación del tipo de cambio y para la prueba de causalidad de los coeficientes del saldo objetivo en la ecuación del tipo de cambio. Por lo tanto, el tipo de cambio causa en el sentido de Granger a la tasa de interés y no viceversa, el saldo objetivo causa en el sentido de Granger a la tasa de interés y viceversa y el tipo de cambio causa al saldo objetivo y viceversa.

Cuadro 3.9 Pruebas de Causalidad de Granger

\begin{tabular}{lcc}
\hline Hipótesis nula & Observaciones & Estadístico- F \\
\hline TIPO DE CAMBIO_ TASA DE INTERÉS & 914 & $10.1018^{*}$ \\
TASA DE INTERÉS_ TIPO DE CAMBIO & 914 & $0.95852^{*}$ \\
SALDO OBJETIVO_ TASA DE INTERÉS & 1053 & 16.0003 \\
TASA DE INTERÉS_ SALDO OBJETIVO & 1053 & $7.05161^{*}$ \\
SALDO OBJETIVO _ TIPO DE CAMBIO & 914 & $2.16534^{*}$ \\
TIPO DE CAMBIO _ SALDO OBJETIVO & 914 & $9.70802^{*}$ \\
\hline
\end{tabular}

${ }^{*}$ Significativo al $1 \%,{ }^{* *}$ Significativo al $5 \%,{ }^{* * *}$ Significativo al $10 \%$

\footnotetext{
${ }^{28}$ En general, para el resto de los rezagos no hubo ninguna correlación superior a $10 \%$ con excepción de aquélla entre la tasa de interés de fondeo y el tipo de cambio de 4 rezagos que resultó de $16 \%$.
} 
Finalmente, procedimos a estimar los vectores autorregresivos utilizando los niveles de estas tres variables. La tasa de interés de Estados Unidos, el índice de la bolsa de valores de Brasil y el "spread" del bono Brady se incluyen como variables exógenas. Estimamos todos los VARS que surgen de modificar el orden entre estas 3 variables en niveles, ${ }^{29}$ considerando 8 rezagos de cada variable. ${ }^{30}$ Debido a que la única diferencia notable entre estos VARs parece provenir del hecho de que el tipo de cambio se especifique antes o después de la tasa de interés en cada VAR, sólo incluimos las estimaciones de dos de ellos en los que esta diferencia se contrasta junto con las funciones de impulso respuesta a 60 días y las descomposiciones de varianza correspondientes. En el VAR-1 el orden de especificación es tasa de fondeo-tipo de cambio-saldo objetivo (cuadros 3.10 y 3.11) y en el VAR-2 el orden de especificación es tipo de cambio-tasa de fondeo-saldo objetivo (cuadros 3.12 y 3.13). Los aspectos más interesantes a resaltar son los siguientes.

Primero, que las estimaciones confirman que un choque en el saldo objetivo anunciado tiene un efecto inverso en la tasa de interés y que un choque en el tipo de cambio tiene un efecto directo en la tasa de interés. Estos dos efectos se observan en todos los vectores autorregresivos con independencia del orden en que se incluyen las variables, lo cual se puede apreciar en las funciones de impulso respuesta y de descomposición de varianzas que se anexan. Sin embargo, conviene observar que las descomposiciones de varianza presentadas en los cuadros 3.11 y 3.13 indican que después de 60 días si bien el porcentaje de la variación debida a variaciones del saldo objetivo es bastante similar en ambas especificaciones (16.1\% y $16.5 \%$, respectivamente) el porcentaje de la variación atribuida a variaciones del tipo de cambio es notablemente menor en el VAR-1 que en el VAR-2 (9.97 y 28.3\%, respectivamente).

Este resultado es congruente, en general, con las estimaciones obtenidas de las regresiones simples. En las funciones de impulso respuesta inclusive se observa que el choque sobre la tasa de fondeo tiene una duración de 15 días, que coincide con las estimaciones que se presentan en la sección 3.2. La contribución porcentual de la variación del saldo objetivo a la variación total de la tasa de fondeo es menor que 17\%. Tanto el VAR-1 como el VAR-2 indican que más de la mitad de la variación total de la tasa de fondeo es atribuida a su propia variación.

Segundo, con respecto a la relación entre el tipo de cambio y la tasa de interés se observa que cuando en el VAR la tasa de interés está antes que el tipo de cambio, un aumento en la tasa de interés primero aumenta el tipo de cambio y luego lo reduce (cuadro 3.10). No obstante, cuando en el VAR el tipo de cambio está antes que la tasa de interés, un aumento en la tasa de interés solamente reduce el tipo de cambio a partir del día 5 (cuadro 3.12). En cuanto a la relación entre el saldo objetivo y el tipo de cambio, con independencia del orden de especificación, se observa que el saldo objetivo tiene un efecto positivo sobre el tipo de cambio, también a partir del día 5. Las descomposiciones de varianza correspondientes indican que después de 60 días el porcentaje de variación asociado a variaciones en el saldo objetivo es $18.3 \%$ en el VAR-1 y $3.3 \%$ en el VAR-2, mientras que los porcentajes de variación asociados a variaciones en el

\footnotetext{
${ }^{29}$ Enders (1995).

${ }^{30}$ El número de rezagos se seleccionó mediante el Criterio de Schwartz.
} 
propio tipo de cambio y a variaciones de la tasa de fondeo son de $65.1 \%$ y $16.7 \%$ en el VAR-1 y $69.5 \%$ y $27.3 \%$ en el VAR-2.

Tercero, el efecto sobre el saldo objetivo de un incremento en el tipo de cambio es negativo; este efecto es pequeño y es mucho más persistente cuando la tasa de fondeo precede al tipo de cambio que cuando éste la procede. El efecto de un choque en la tasa de interés es positivo y persistente con independencia del orden de especificación. Asimismo, cabe mencionar que las variaciones en la tasa de fondeo representan un porcentaje mayor de la variación en el saldo objetivo que las variaciones en el tipo de cambio. En particular, estas últimas representan un porcentaje menor que $7 \%$ en el VAR-1 y menor que $4 \%$ en el VAR-2.

La muestra disponible para analizar la dinámica de estas variables bajo el régimen de saldos acumulados abarca solamente cuatro años, los cuales pueden ser insuficientes para captar movimientos de largo plazo de las variables y, en consecuencia, la especificación de los VARs en niveles pudiera ser inadecuada y ésta podría ser la razón de las diferencias en los efectos reportados. Por ende, estimamos el VAR-1 y el VAR-2 en primeras diferencias y encontramos que la asimetría en el efecto sobre el tipo de cambio asociado a variaciones en la tasa de fondeo persiste en la estimación en primeras diferencias. En contraste, la diferencia en la persistencia del efecto sobre el saldo acumulado objetivo asociado a variaciones en el tipo de cambio no: una reducción exógena del tipo de cambio produce una reducción en el saldo objetivo anunciado que representa menos de 7\% de la varianza del saldo acumulado. El resto de los resultados coincide con los de la estimación en niveles, aunque el efecto sobre la tasa de fondeo asociado al "corto," además de transitorio, apenas resulta significativamente distinto de cero y representa el $14 \%$ de la varianza de la misma. ${ }^{31}$

\footnotetext{
${ }^{31}$ Estas estimaciones están disponibles a solicitud del lector.
} 


\section{Cuadro 3.10 Funciones de Impulso Respuesta del VAR-1}

Tasa de Fondeo - Tipo de Cambio - Saldo Objetivo

Respuesta de TFON a TFON
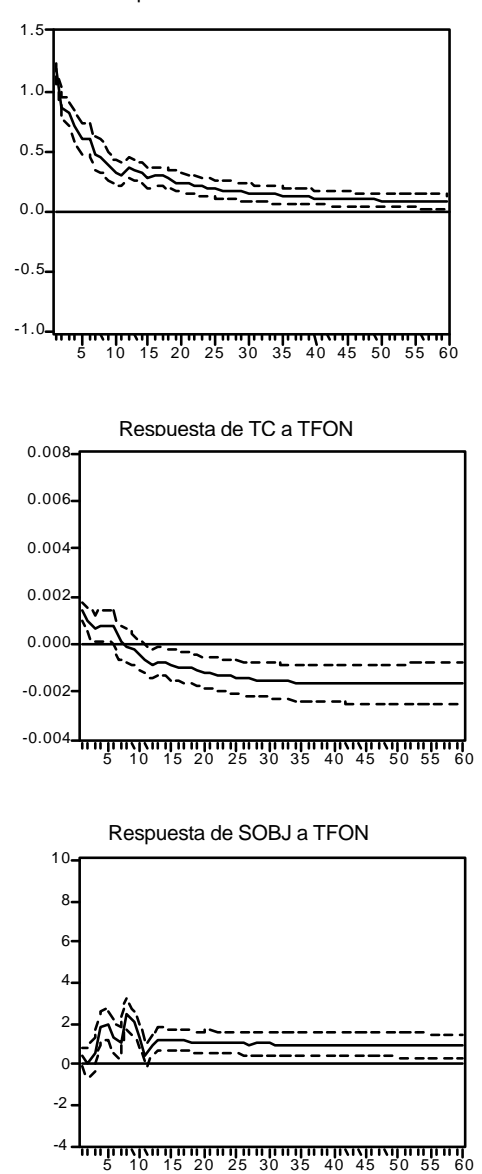

Respuesta a una Innovación de una Desv. Est \pm 2 E.S.
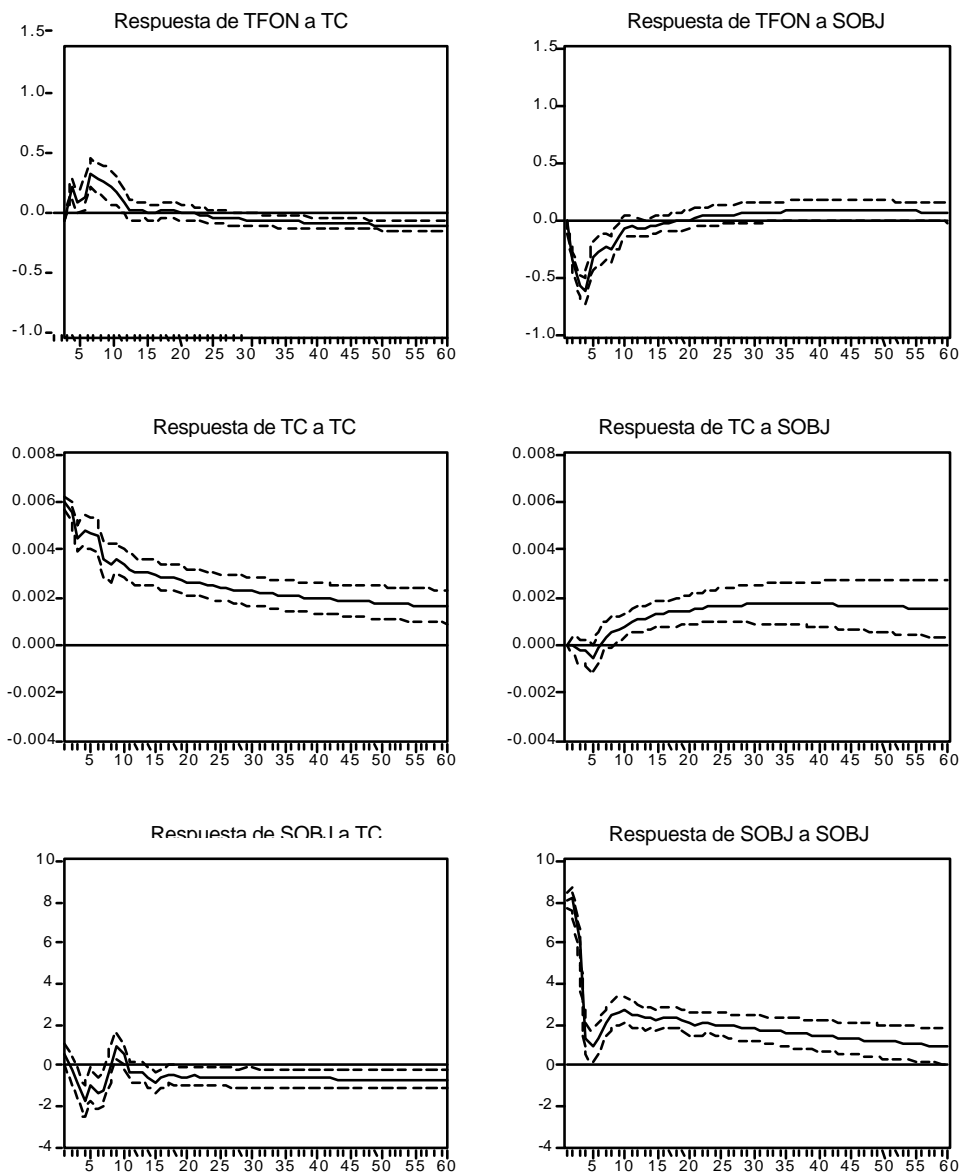
Cuadro 3.11 Descomposición de Varianzas del VAR-1

Tasa de fondeo - Tipo de cambio - Saldo objetivo

\begin{tabular}{lcccc}
\hline Descomposición de la varianza de TFON & & & \\
\hline Periodo & S.E. & TFON & TC & SOBJ \\
\hline 1 & 1.17522 & 100.0000 & 0.00000 & 0.00000 \\
5 & 2.21313 & 74.51070 & 6.50811 & 18.98118 \\
10 & 2.56148 & 71.25056 & 11.24791 & 17.50153 \\
15 & 2.66663 & 72.83673 & 10.76651 & 16.39676 \\
20 & 2.73663 & 73.79269 & 10.61506 & 15.59224 \\
25 & 2.77667 & 74.39339 & 10.39733 & 15.20928 \\
30 & 2.80404 & 74.68652 & 10.20104 & 15.11244 \\
35 & 2.82547 & 74.75586 & 10.05337 & 15.19077 \\
40 & 2.84354 & 74.67691 & 9.95753 & 15.36555 \\
45 & 2.85944 & 74.51323 & 9.90891 & 15.57786 \\
50 & 2.87371 & 74.30924 & 9.90048 & 15.79028 \\
55 & 2.88660 & 74.09367 & 9.92473 & 15.98160 \\
60 & 2.89831 & 73.88383 & 9.97456 & 16.14161 \\
\hline Descomposición de la varianza de TC & & & \\
\hline Periodo & S.E. & TFON & TC & SOBJ \\
\hline 1 & 0.00610 & 5.19131 & 94.80868 & 0.00000 \\
5 & 0.01170 & 3.32463 & 96.30834 & 0.36702 \\
10 & 0.01449 & 2.55967 & 96.45982 & 0.98051 \\
15 & 0.01632 & 3.16037 & 93.64120 & 3.19842 \\
20 & 0.01790 & 4.41163 & 89.86996 & 5.71840 \\
25 & 0.01933 & 6.13787 & 85.56827 & 8.29386 \\
30 & 0.02063 & 7.99924 & 81.34831 & 10.65244 \\
35 & 0.02182 & 9.80824 & 77.52496 & 12.66680 \\
40 & 0.02291 & 11.48861 & 74.18036 & 14.33103 \\
45 & 0.02389 & 13.01039 & 71.31210 & 15.67750 \\
50 & 0.02479 & 14.37292 & 68.87378 & 16.75330 \\
55 & 0.02561 & 15.58787 & 66.80680 & 17.60533 \\
60 & 0.02635 & 16.67073 & 65.05382 & 18.27545 \\
\hline Descomposición de la varianza de SOBJ & & & \\
\hline Periodo & & TFON & TC & SOBJ \\
\hline 1 & 2.08801 & 0.20013 & 0.52068 & 99.27918 \\
5 & 13.47629 & 3.95585 & 2.81857 & 93.22557 \\
10 & 15.09540 & 9.89796 & 4.23501 & 85.86701 \\
15 & 16.18346 & 10.63771 & 4.24188 & 85.12041 \\
20 & 17.16420 & 11.51657 & 4.26769 & 84.21574 \\
25 & 17.94224 & 12.30769 & 4.38804 & 83.30427 \\
30 & 18.59437 & 12.92206 & 4.64591 & 82.43203 \\
35 & 19.14713 & 13.49845 & 4.95704 & 81.54451 \\
40 & 19.61642 & 14.05671 & 5.31311 & 80.63017 \\
50 & 20.01921 & 14.60132 & 5.69660 & 79.70207 \\
55 & 20.36826 & 15.13827 & 6.09849 & 78.76323 \\
\hline & 20.67346 & 15.66834 & 6.51136 & 77.82029 \\
& & & & \\
\hline 5 & 16.19089 & 6.92910 & 76.88000 \\
\hline
\end{tabular}




\section{Cuadro 3.12 Funciones de Impulso Respuesta del VAR-2}

Tipo de cambio - Tasa de fondeo - Saldo objetivo

Respuesta a una Innovación de una Des. Est. \pm 2 E.S
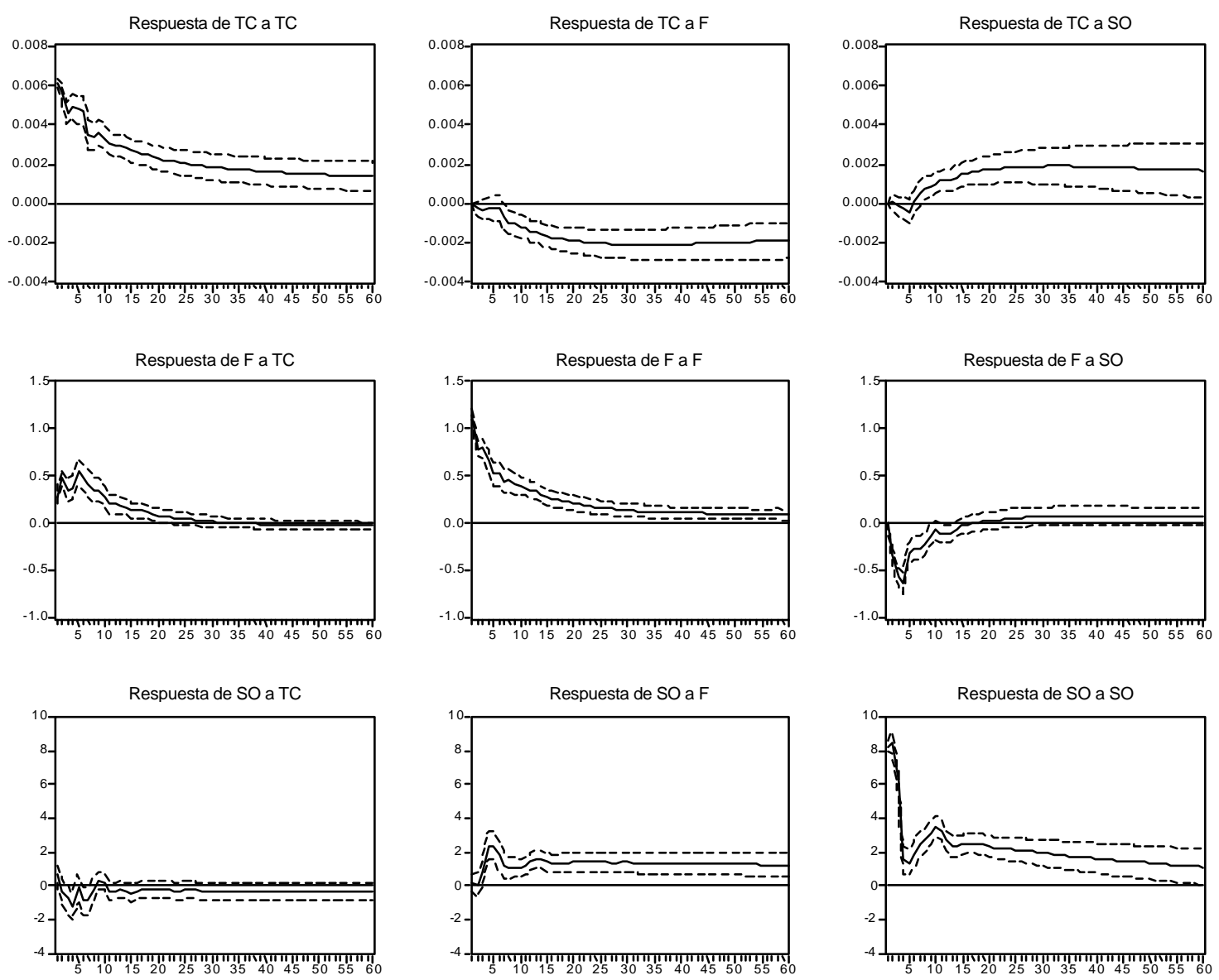
Cuadro 3.13 Descomposición de Varianzas del VAR-2

Tipo de cambio - Tasa de fondeo - Saldo objetivo

\begin{tabular}{lcccc}
\hline Descomposición de la varianza de TC & & & \\
\hline Periodo & S.E. & TC & TFON & SOBJ \\
\hline 1 & 0.0552 & 100.0000 & 0.0000 & 0.00000 \\
5 & 0.1142 & 99.5000 & 0.0284 & 0.4711 \\
10 & 0.1485 & 98.7723 & 0.8436 & 0.3839 \\
15 & 0.1669 & 96.0115 & 3.3121 & 0.6763 \\
20 & 0.1810 & 92.1278 & 6.6358 & 1.2362 \\
25 & 0.1931 & 88.0817 & 10.1156 & 1.8025 \\
30 & 0.2038 & 84.2756 & 13.4337 & 2.2905 \\
35 & 0.2136 & 80.8721 & 16.4604 & 2.6674 \\
40 & 0.2225 & 77.9001 & 19.1634 & 2.9364 \\
45 & 0.2308 & 75.3253 & 21.5601 & 3.1145 \\
50 & 0.2386 & 73.0949 & 23.6841 & 3.2209 \\
55 & 0.2458 & 71.1548 & 25.5722 & 3.2728 \\
60 & 0.2525 & 69.4569 & 27.2584 & 3.2845 \\
\hline Descomposición de la varianza de Fondeo & & & \\
\hline Periodo & S.E. & TC & TFON & SOBJ \\
\hline 1 & 1.1591 & 6.7072 & 93.2927 & 0.0000 \\
5 & 2.4635 & 21.3825 & 58.7938 & 19.8232 \\
10 & 3.0096 & 29.6024 & 52.6010 & 17.7964 \\
15 & 3.1835 & 29.4839 & 53.0143 & 17.5017 \\
20 & 3.2456 & 29.2575 & 53.5539 & 17.1884 \\
25 & 3.2732 & 28.9379 & 54.0631 & 16.9988 \\
30 & 3.2876 & 28.6995 & 54.4369 & 16.8635 \\
35 & 3.2974 & 28.5382 & 54.6970 & 16.7647 \\
40 & 3.3053 & 28.4363 & 54.8764 & 16.6872 \\
45 & 3.3125 & 28.374 & 55.0028 & 16.6222 \\
50 & 3.3193 & 28.3396 & 55.0956 & 16.5647 \\
55 & 3.3259 & 28.3208 & 55.1675 & 16.5116 \\
60 & 3.3322 & 28.3123 & 55.2263 & 16.4613 \\
\hline Descomposición de la varianza de SOBJ & & & \\
\hline Periodo & S.E. & TC & TFON & SOBJ \\
\hline 1 & 8.8805 & 0.3775 & 0.0325 & 99.5898 \\
5 & 15.0758 & 2.0705 & 5.6099 & 92.3195 \\
10 & 16.8099 & 2.7642 & 7.2912 & 89.9445 \\
15 & 18.3322 & 2.6986 & 9.2583 & 88.0430 \\
20 & 19.5339 & 2.6156 & 10.5855 & 86.7988 \\
25 & 20.5320 & 2.6055 & 11.9619 & 85.4324 \\
30 & 21.3899 & 2.6292 & 13.1619 & 84.2088 \\
35 & 22.1318 & 2.6934 & 14.2743 & 83.0322 \\
40 & 22.7823 & 2.7863 & 15.3053 & 81.9083 \\
45 & 23.3580 & 2.9036 & 16.2701 & 80.8262 \\
50 & 23.8720 & 3.0414 & 17.1784 & 79.7801 \\
60 & 24.3347 & 3.1962 & 18.0373 & 78.7663 \\
& 24.7541 & 3.3654 & 18.8527 & 77.7818 \\
\hline & & & &
\end{tabular}


En resumen, los resultados sobre la causalidad cruzada entre el tipo de cambio y la tasa de interés de fondeo no son concluyentes. Las pruebas de causalidad de Granger indican que hay causalidad del tipo de cambio hacia la tasa de interés pero no viceversa, pero las funciones de impulso respuesta de los vectores autorregresivos indican que la respuesta observada de una de estas variables con respecto a un choque en la otra depende notablemente del orden de especificación. Por otra parte, en las pruebas de causalidad de Granger y en los vectores autorregresivos hay evidencia que sugiere que el objetivo de saldo acumulado anunciado está más relacionado con los movimientos en la tasa de fondeo que con los movimientos en el tipo de cambio.

En cuanto al saldo objetivo anunciado, las funciones de impulso respuesta confirman el resultado de la sección anterior, es decir, que un "corto" tiene un efecto negativo y transitorio sobre la tasa de fondeo. Las funciones no indican un efecto significativo de choques en esta variable sobre el tipo de cambio. El resto de los resultados provenientes de los vectores autorregresivos son compatibles con los que se presentan en las secciones 3.2 y 3.3, lo cual incrementa la confianza que se puede tener en la estructura impuesta en esas estimaciones.

\section{Análisis de los efectos sobre las tasas de interés de los CETEs a 28, 91, 182 y 364 días}

\subsection{Descripción de los datos}

En esta sección utilizamos datos semanales, debido a que esa es la periodicidad de las subastas de los Certificados de Tesorería (CETEs). En el periodo de análisis hubo dos lapsos, entre octubre y diciembre de 1995 y entre septiembre y diciembre de 1998, durante los cuales no hubo subastas de CETEs a 182 y a 364 días. Fuera de esos dos lapsos, estas variables se mueven juntas, inclusive con la tasa de interés de fondeo, como se puede apreciar al comparar con la gráfica 2.1 .

Gráfica 4.1 Tasas de Interés de los CETEs a 28, 91, 182 y 364 días

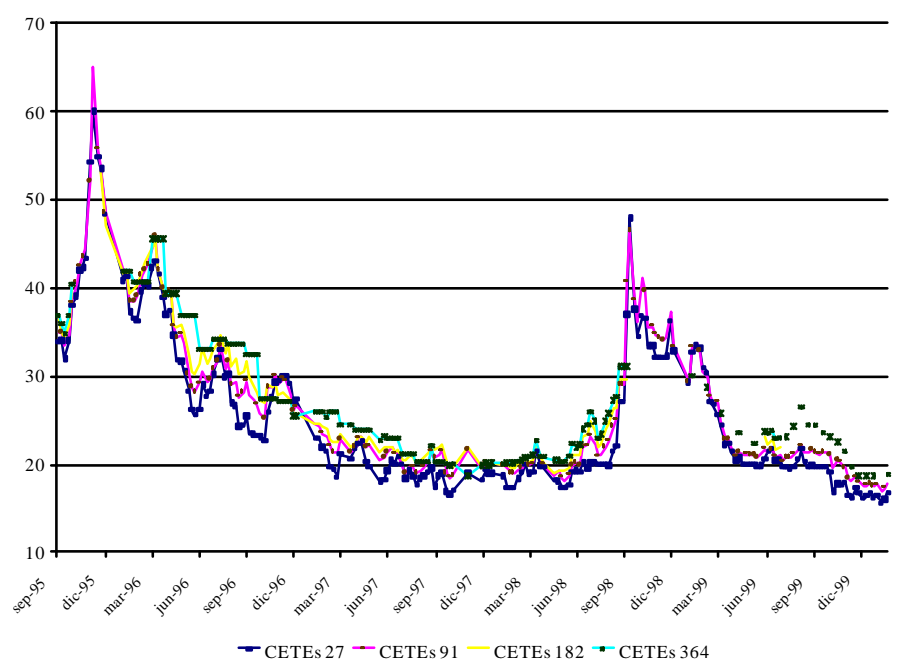


No sólo la correlación de estas variables es elevada, como indican los coeficientes de correlación entre ellas (cuadro 4.1). Las pruebas de raíz unitaria de Dickey-Fuller Aumentada (ADF) y de Phillips-Perron (PP) muestran que cada una de las tasas de CETES es no estacionaria pero que la diferencia entre cada par de tasas, excepto entre la tasa de los CETEs a 181 días y la de los CETEs a 91 días, si es estacionaria a los niveles de significancia convencionales. ${ }^{32}$ Esto sugiere la existencia de cointegración, es decir, de una combinación lineal estacionaria de largo plazo entre las tasas de interés.

\subsection{1}

4.1.2 Cuadro 4.1 Matriz de Correlacion entre las Tasas de Interés

\begin{tabular}{lccccc}
\hline & TFON & CETEs a & CETEs a & CETEs a & CETES a \\
& & 28 días & 91 días & 182 días & 364 días \\
\hline Fondeo & 1.00000 & 0.97477 & 0.96322 & 0.93911 & 0.89714 \\
CETEs a 28 días & 0.97477 & 1.00000 & 0.98891 & 0.96623 & 0.93092 \\
CETEs a 91 días & 0.96322 & 0.98891 & 1.00000 & 0.98235 & 0.95412 \\
CETES a 182 días & 0.93911 & 0.96620 & 0.98295 & 1.00000 & 0.97883 \\
CETES a 364 días & 0.89714 & 0.93092 & 0.95412 & 0.978838 & 1.00000 \\
\hline
\end{tabular}

4.1.3 Cuadro 4.2 Pruebas de Raíz Unitaria en niveles

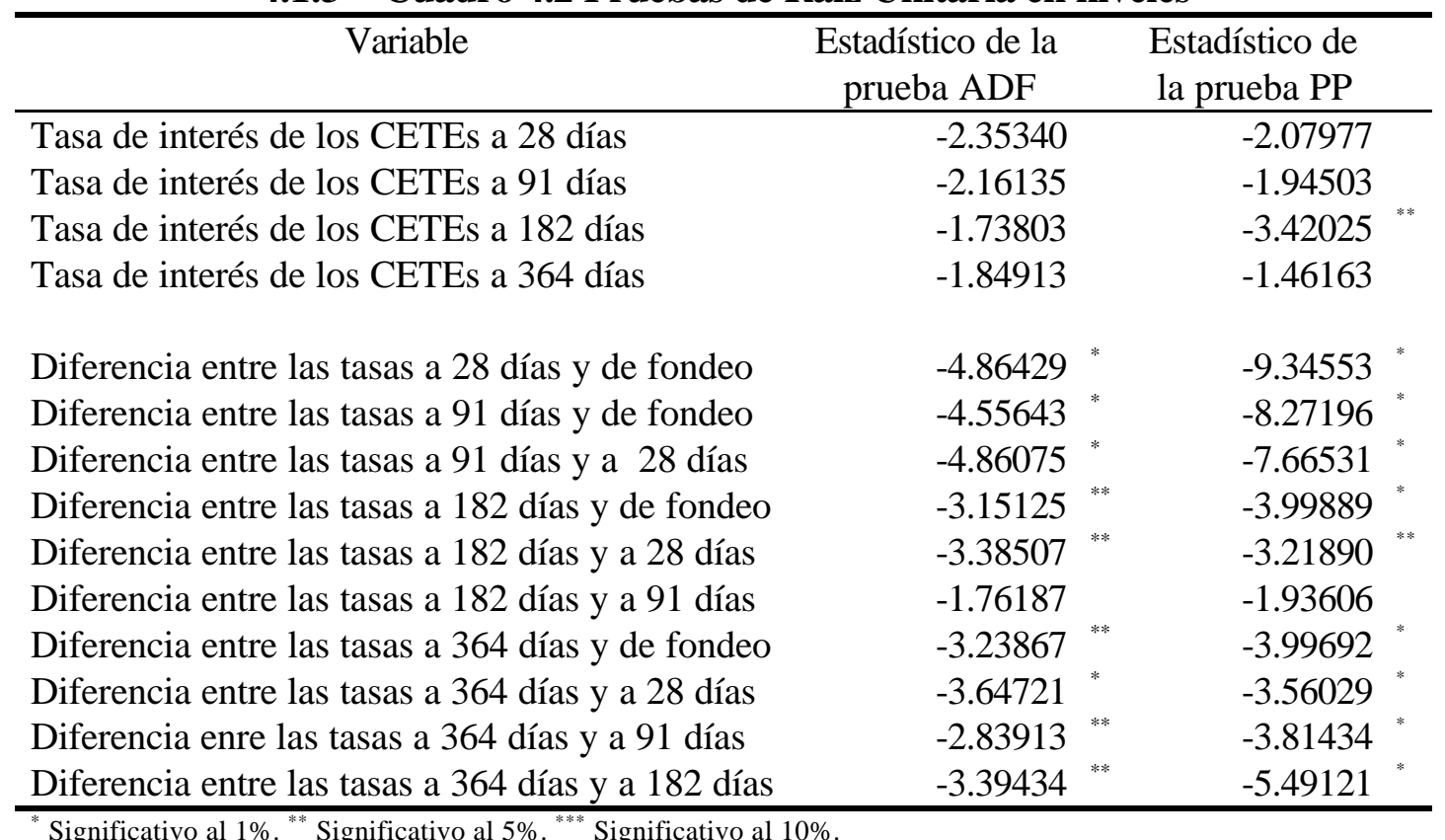

Una característica importante de las variables cointegradas es que sus trayectorias en el tiempo están influidas por cualquier desviación del equilibrio de largo plazo. Después de todo, si un sistema debe retornar a su equilibrio de largo plazo, los movimientos de cuando menos algunas de las variables del sistema deben responder a la magnitud del desequilibrio. Las teorías sobre la estructura de tasas de interés implican una relación de largo plazo entre las tasas largas y cortas. En ausencia de posibilidades de arbitraje, la diferencia de equilibrio entre las tasas de largo plazo

\footnotetext{
${ }^{32}$ Las pruebas de Dickey-Fuller y Phillips-Perron que realizamos son en niveles e incluyen una constante pero no una tendencia.
} 
y las de corto plazo se debe tan sólo a primas de riesgo o de liquidez de los diferentes activos. Si la brecha entre la tasa de interés de largo plazo y la de corto plazo es "grande" relativa a la relación de largo plazo, la tasa de corto plazo en última instancia debe aumentar con respecto a la tasa de largo plazo. Esta brecha puede reducirse debido a (1) un aumento en la tasa de corto plazo y/o una reducción en la tasa de largo plazo, (2) un aumento en la tasa de largo plazo pero un aumento aún mayor en la tasa de corto plazo, o (3) una reducción en la tasa de largo plazo y una reducción aún menor en la tasa de corto plazo. Sin la especificación dinámica completa del modelo no es posible determinar cual de estas posibilidades ocurrirá. Una alternativa para aproximarse a este problema es mediante modelos de corrección de error.

\subsection{Modelos de Corrección de Error}

En un modelo de corrección de error, la dinámica de corto plazo de las variables de un sistema están influidas explícitamente por la desviación del equilibrio de largo plazo. Suponiendo que ambas tasas de interés tienen una raíz unitaria (lo cual no contradice las pruebas del cuadro 4.2), un modelo simple de corrección de error aplicable a la estructura de tasas de interés es:

$$
\begin{gathered}
\Delta r_{s t}=\alpha_{s}\left(r_{l t-1}-\beta r_{s t-1}-C\right)+\gamma_{s} \cdot X_{s}+\varepsilon_{s t} \\
\Delta r_{l t}=-\alpha_{l}\left(r_{l t-1}-\beta r_{s t-1}-C\right)+\gamma_{l} \cdot X_{l}+\varepsilon_{l t},
\end{gathered}
$$

donde $r_{l t}$ y $r_{s t}$ son las tasas de largo plazo y de corto plazo, respectivamente. $X_{s}$ y $X_{l}$ son vectores que contienen otras variables explicativas de la dinámica de corto plazo de estas tasas. Los dos términos representados por $\varepsilon_{s t}$ y $\varepsilon_{l t}$ son términos de error ruido blanco que pueden estar correlacionados, $\alpha_{s}, \alpha_{l}$ y $\beta$ son parámetros positivos y $C$ es la diferencia de largo plazo debida a primas de riesgo o liquidez entre la tasa de largo plazo y la de corto plazo. De esta manera, las tasas de interés de corto y largo plazo cambian en respuesta a choques estocásticos (representados por $\varepsilon_{s t}$ y $\varepsilon_{l t}$ ) y a desviaciones del equilibrio de largo plazo del periodo anterior. Ceateris paribus, si ocurre una desviación positiva (de manera que $r_{t t-1}-\beta r_{s t}>C$ ) entonces la tasa de interés de corto plazo sube y la tasa de interés de largo plazo baja. El término $r_{l t-1^{-}} \beta r_{s t 1^{-}}$ $C$ se denomina término de corrección de error y el equilibrio de largo plazo se obtiene cuando $r_{l t-}$ ${ }_{1}-\beta r_{s t}=C$. $\beta$ es el vector de cointegración del sistema, que de según la teoría económica en este modelo debe ser (1), debido a que en el largo plazo no deben existir oportunidades de arbitraje.

En los cuadros 4.3a, b, c y d se presentan los resultados provenientes de los modelos de corrección de error para cada una de las tasas de interés de los CETEs como tasa de interés de largo plazo y la tasa de interés de fondeo como tasa de interés de corto plazo, incluyendo como variables independientes, en adición al término de corrección de error, las variables utilizadas en la sección 3. La variable $\Delta \mathrm{T}_{1}$ denota la tasa de interés de los CETEs a $i$ días y la variable $T_{i} T F$ al término de corrección de error entre la tasa de interés de los CETEs a $i$ días y la tasa de interés de fondeo. 
El resultado más importante a destacar es que en los cuatro modelos los coeficientes asociados al término de corrección de error que se obtienen son congruentes con la teoría: el coeficiente asociado al término de corrección de error en cada ecuación de la tasa de CETEs tiene signo negativo y significativo, como indica la ecuación 3, excepto en la regresión para la tasa a 182 días en la que no es significativamente distinto de cero (lo cual se considera como una prueba indirecta de que el término de corrección de error es no estacionario, como revelan las pruebas del cuadro 4.2). A su vez, aquél en cada ecuación de la tasa de fondeo es positivo y significativo, como indica la ecuación 2. Por tanto, la hipótesis de que el vector de cointegración es (1) no es rechazada por los datos.

\section{Cuadro 4.3a Resultados de los Modelos de Corrección de Error} de la Tasas de CETEs a 28 días $^{\mathrm{a}}$

\begin{tabular}{|c|c|c|}
\hline & $\Delta \mathrm{T} 28$ & $\begin{array}{c}\triangle \mathrm{TFONDE} \\
\mathrm{O}\end{array}$ \\
\hline $\mathrm{C}$ & -0.14973 & -0.44913 \\
\hline T28TF(t-1) & -0.37540 & 0.26164 \\
\hline$\Delta \mathrm{SOBJ}(\mathrm{t})$ & -0.02009 & -0.02450 \\
\hline$\Delta \mathrm{S} 0 \mathrm{BJ}(\mathrm{t}-1)$ & -0.03490 & -0.02739 \\
\hline$\Delta \mathrm{S} O \mathrm{BJ}(\mathrm{t}-2)$ & -0.01924 & \\
\hline$\Delta \mathrm{S} 0 \mathrm{BJ}(\mathrm{t}-3)$ & -0.02260 & \\
\hline$\Delta \mathrm{S} 0 \mathrm{BJ}(\mathrm{t}-4)$ & -0.01078 & $0.00971^{*}$ \\
\hline$\Delta \mathrm{S} 0 \mathrm{BJ}(\mathrm{t}-5)$ & & $0.01554^{*}$ \\
\hline$\Delta \mathrm{LTC}(\mathrm{t})$ & 17.21095 & $37.95068^{*}$ \\
\hline$\Delta \mathrm{LTC}(\mathrm{t}-1))$ & & 29.02330 * \\
\hline$\Delta \mathrm{LTC}(\mathrm{t}-2))$ & 26.33941 & \\
\hline$\Delta \mathrm{LTC}(\mathrm{t}-3))$ & 10.05374 & \\
\hline$\Delta \mathrm{LTC}(\mathrm{t}-6))$ & & $-18.21127^{* *}$ \\
\hline$\Delta B 30(t-6)$ & & -2.22126 \\
\hline$\Delta \operatorname{LRUS}(\mathrm{t})$ & -2.22258 & \\
\hline$\Delta \operatorname{LRUS}(\mathrm{t}-1)$ & 2.08122 & \\
\hline$\Delta \operatorname{LRUS}(\mathrm{t}-2)$ & 3.17342 & \\
\hline$\Delta \operatorname{LRUS}(\mathrm{t}-6)$ & 2.37811 & \\
\hline$\Delta \operatorname{LBRA}(\mathrm{t}-1)$ & & $4.23833^{\text {*** }}$ \\
\hline$\Delta \operatorname{LBRA}(\mathrm{t}-3)$ & & $3.28367^{* *}$ \\
\hline$\Delta \operatorname{LBRA}(\mathrm{t}-6)$ & -1.66495 & \\
\hline$\triangle \operatorname{SPREAD}(\mathrm{t})$ & 0.92421 & $1.35657^{*}$ \\
\hline$\Delta \operatorname{SPREAD}(\mathrm{t}-1)$ & & 0.52299 \\
\hline$\triangle \operatorname{SPREAD}(\mathrm{t}-2)$ & & $0.37749^{* *}$ \\
\hline $\mathrm{R}^{2}$ & 0.72027 & 0.55374 \\
\hline $\mathrm{R}^{2}$ Ajustada & 0.69696 & 0.51865 \\
\hline $\mathrm{AIC}$ & 3.53430 & 3.86253 \\
\hline SBC & 3.80567 & 4.11611 \\
\hline Número de obs. & 196 & 193 \\
\hline
\end{tabular}


Asimismo, se observa que el coeficiente del término de corrección de error de la tasa de largo plazo se reduce en valor absoluto conforme se incrementa el plazo de la tasa de CETEs de 28 a 364 días. De acuerdo con los coeficientes obtenidos el 99\% de una desviación entre la tasa de interés a 28 días y la tasa de fondeo tarda aproximadamente 10 semanas en ser asimilado, mientras que una desviación entre la tasa a 91 días y la tasa de fondeo tarda aproximadamente 15 semanas y una desviación entre la tasa a 364 días y la tasa de fondeo tarda aproximadamente 39 semanas. ${ }^{33}$ Esto sugiere que la información nueva se refleja de manera más inmediata en las tasas de más corto plazo.

\section{Cuadro 4.3b Resultados de los Modelos de Corrección de Error de la Tasa de CETEs a 91 días $^{\text {a }}$}

\begin{tabular}{|c|c|c|}
\hline & $\Delta \mathrm{T} 91$ & $\triangle \mathrm{TFONDEO}$ \\
\hline $\mathrm{C}$ & 0.285041 & -0.677699 \\
\hline T91TF(t-1) & -0.270618 & 0.190268 \\
\hline$\Delta \mathrm{S} 0 \mathrm{BJ}(\mathrm{t})$ & & -0.026244 \\
\hline$\Delta \mathrm{S} 0 \mathrm{BJ}(\mathrm{t}-1)$ & -0.038457 & -0.032177 \\
\hline$\Delta \mathrm{S} 0 \mathrm{BJ}(\mathrm{t}-2)$ & -0.014451 & $* *$ * \\
\hline$\Delta \mathrm{S} 0 \mathrm{BJ}(\mathrm{t}-3)$ & -0.013892 & ** \\
\hline$\Delta \mathrm{SOBJ}(\mathrm{t}-6)$ & & -0.010485 \\
\hline$\Delta \mathrm{LTC}(\mathrm{t})$ & 22.58031 & 42.95504 \\
\hline$\Delta \mathrm{LTC}(\mathrm{t}-1)$ & & 28.86685 \\
\hline$\Delta \mathrm{LTC}(\mathrm{t}-2)$ & 21.86257 & ** \\
\hline$\Delta \mathrm{LTC}(\mathrm{t}-6)$ & & -22.08625 \\
\hline$\Delta \mathrm{B} 30(\mathrm{t}-6)$ & & -2.831569 \\
\hline$\Delta \operatorname{LRUS}(\mathrm{t}-2)$ & 3.261143 & " \\
\hline$\Delta \operatorname{LRUS}(\mathrm{t}-3)$ & -1.507983 & ** \\
\hline$\Delta \mathrm{LBRA}(\mathrm{t}-3)$ & & 2.951014 \\
\hline$\triangle \mathrm{SPREAD}(\mathrm{t})$ & 1.059863 & 1.033387 \\
\hline $\mathrm{R}^{2}$ & 0.635278 & 0.527719 \\
\hline $\mathrm{R}^{2}$ Ajustada & 0.618002 & 0.501770 \\
\hline $\mathrm{AIC}$ & 3.550279 & 3.877780 \\
\hline SBC & 3.715195 & 4.063736 \\
\hline Número de obs. & 200 & 193 \\
\hline
\end{tabular}

En los cuatro modelos también se observa que tanto los cambios en el saldo objetivo como los cambios en la tasa de depreciación pasados afectan más a las tasas de más corto plazo que a las de más largo plazo. De acuerdo con los cuadros 4.3.a y 4.3.b, la suma de coeficientes significativos asociados al objetivo de saldo acumulado en las ecuaciones de las tasas de CETEs a

\footnotetext{
${ }^{33}$ Las velocidades de ajuste se calcularon utilizando los coeficientes de corrección de error mediante la siguiente fórmula:, $\tau=\log (1-\omega) / \log \left(1-\not \alpha_{i}^{\prime}\right)$ en donde $\tau$ es la velocidad de ajuste, $\alpha$ es el coeficiente de corrección de error y $\omega$ es el porcentaje de la desviación asimilado.
} 
28 días y a 91 días es -0.10 y -0.067 puntos porcentuales respectivamente. Para la tasa de CETEs a 28 días esta suma inclusive implica un efecto de mayor magnitud absoluta que para la tasa de fondeo que en la ecuación de CETEs a 28 días es -0.026 puntos porcentuales y en la de CETEs a 91 días es -0.069 puntos porcentuales. ${ }^{34}$ A su vez, según los cuadros 4.3.c y 4.3.d, la suma de coeficientes asociadas al saldo objetivo en la ecuación de CETEs a 182 días es -0.049 y en la ecuación de CETEs a 364 días no es significativamente distinta de cero, ambas magnitudes menores que las correspondientes para la tasa de fondeo, que es -0.072 y -0.12 respectivamente. Estos resultados significan que un "corto" tiende a hacer menos empinada la curva de tasas de interés de la subasta primaria, lo que a su vez sugiere que esta medida restrictiva se asocia a una reducción de las expectativas de inflación futura.

Este patrón de un efecto decreciente sobre las tasas de CETEs también se obtiene para el tipo de cambio. La suma de coeficientes significativos es 53.6, 44.4, 32.8 y cero puntos base respectivamente para las tasas de CETEs a 28, 91, 182 y 364 días. Pero este patrón es menos claro para el resto de las variables independientes, si bien se observa que las variables explicativas que son significativas en estas regresiones coinciden en buena medida con los resultados de la sección 3.

Los estadísticos de $R^{2}$ y $R^{2}$ ajustada también sugieren un menor poder explicativo en las ecuaciones de las tasas de más largo plazo: éstos son 0.72 y 0.69 , respectivamente, en la ecuación de CETEs a 28 días y se reducen progresivamente hasta 0.16 y 0.15 en la ecuación de CETEs a 364 días. Sin embargo, es importante destacar que para las estimaciones correspondientes a las tasas de CETEs a 182 y 364 días se tienen menos observaciones que para las correspondientes a 28 y 91 días. En consecuencia, parte del poder predictivo progresivamente menor de las variables explicativas podría deberse a este problema. Sin embargo, de aceptarse el hecho de que el saldo objetivo anunciado y el tipo de cambio tienen un efecto menor en las tasas de más largo plazo, queda abierta la pregunta sobre el conjunto de variables que determinan estas tasas. En estudios futuros será deseable incluir otras variables explicativas en las regresiones de las tasas de más largo plazo. La literatura sobre este tema menciona como posibles candidatas, entre otras, las expectativas de inflación y de crecimiento económico.

\footnotetext{
${ }^{34}$ Una conjetura sobre la posible causa de este patrón es que hay más manipulación por parte de los agentes económicos en el mercado secundario en el que se fija la tasa de fondeo que en la subasta primaria en la que se determinan las tasas de los CETEs.
} 


\subsubsection{Cuadro 4.3c Resultados de los Modelos de Corrección de Error} 4.2.2 de la Tasa de CETEs a 182 días $^{\mathbf{a}}$

\begin{tabular}{|c|c|c|}
\hline & $\Delta \mathrm{T} 182$ & $\triangle \mathrm{TFONDEO}$ \\
\hline $\mathrm{C}$ & -0.25127 & -0.84047 \\
\hline $\mathrm{T} 182 \mathrm{TF}(\mathrm{t}-1)$ & 0.00701 & 0.19869 \\
\hline$\Delta \mathrm{S} 0 \mathrm{BJ}(\mathrm{t})$ & & -0.08985 \\
\hline$\Delta \mathrm{S} 0 \mathrm{BJ}(\mathrm{t}-1)$ & & 0.05663 \\
\hline$\Delta \mathrm{SOBJ}(\mathrm{t}-3)$ & -0.03491 & \\
\hline$\Delta \mathrm{S} 0 \mathrm{BJ}(\mathrm{t}-4)$ & -0.01404 & -0.01743 \\
\hline$\Delta \mathrm{S} 0 \mathrm{BJ}(\mathrm{t}-6)$ & & -0.02094 \\
\hline$\Delta \mathrm{LTC}(\mathrm{t})$ & 32.83748 & 34.78875 \\
\hline$\Delta \mathrm{B} 30(\mathrm{t}-6))$ & & -2.52340 \\
\hline$\Delta \operatorname{LRUS}(\mathrm{t}))$ & & 3.21954 \\
\hline$\Delta \operatorname{LBRA}(\mathrm{t}-1)$ & & 5.43798 \\
\hline$\triangle \mathrm{SPREAD}(\mathrm{t})$ & 0.53067 & 1.19548 \\
\hline$\triangle \operatorname{SPREAD}(\mathrm{t}-1)$ & & 1.28620 \\
\hline $\mathrm{R}^{2}$ & 0.44234 & 0.56720 \\
\hline $\mathrm{R}^{2}$ Ajustada & 0.41930 & 0.53141 \\
\hline AIC & 2.94714 & 3.59833 \\
\hline SBC & 3.08151 & 3.84468 \\
\hline Número de obs. & 127 & 145 \\
\hline
\end{tabular}

Finalmente, hay que señalar que estas regresiones exhiben residuales bien comportados. Para todas ellas se obtiene que el correlograma de residuales simples no indica autocorrelación y que las pruebas de heteroscedasticidad ARCH LM tampoco indican que se rechace la hipótesis de cero efectos ARCH para niveles de significancia menores al 5\% (apéndice). Tampoco se observan problemas severos de estabilidad en los coeficientes en las pruebas que realizamos. ${ }^{35}$

\footnotetext{
${ }^{35}$ Estas pruebas están disponibles a petición del lector.
} 


\subsubsection{Cuadro 4.3d Resultados de los Modelos de Corrección de Error de la Tasa de CETEs a 364 días}

\begin{tabular}{|c|c|c|}
\hline & $\Delta \mathrm{T} 364$ & $\triangle \mathrm{TFONDEO}$ \\
\hline $\mathrm{C}$ & 0.32671 & -0.77886 \\
\hline T364TF(t-1) & -0.10548 & 0.14069 \\
\hline$\Delta \mathrm{S} 0 \mathrm{BJ}(\mathrm{t})$ & & -0.08970 \\
\hline$\Delta \mathrm{S} 0 \mathrm{BJ}(\mathrm{t}-1)$ & & 0.03969 \\
\hline$\Delta \mathrm{S} 0 \mathrm{BJ}(\mathrm{t}-3)$ & & -0.04972 \\
\hline$\Delta \mathrm{S} 0 \mathrm{BJ}(\mathrm{t}-6)$ & & -0.02262 \\
\hline$\Delta \mathrm{LTC}(\mathrm{t})$ & & 35.93825 \\
\hline$\Delta \mathrm{B} 30(\mathrm{t}-6))$ & & -3.21101 \\
\hline$\Delta \operatorname{LRUS}(\mathrm{t})$ & & 2.44388 \\
\hline$\Delta \mathrm{SPREAD}(\mathrm{t})$ & & 0.87520 \\
\hline$\Delta \operatorname{SPREAD}(\mathrm{t}-1)$ & 0.55308 & 1.13790 \\
\hline $\mathrm{R}^{2}$ & 0.16340 & 0.52133 \\
\hline $\mathrm{R}^{2}$ Ajustada & 0.15001 & 0.48507 \\
\hline AIC & 3.09957 & 3.64277 \\
\hline SBC & 3.16641 & 3.87068 \\
\hline Número de obs. & 128 & 143 \\
\hline
\end{tabular}

Para completar este análisis, las gráficas $4.4 \mathrm{a}, \mathrm{b}, \mathrm{c}$ y d muestran la trayectoria de ajuste de las tasas de interés ante un "corto" de 20 millones de pesos. Para asignar el valor de equilibrio de largo plazo de las tasas de interés tomamos los valores del 27 de enero de 2000, fecha correspondiente al anuncio de los resultados de la última subasta primaria de la muestra. Cada gráfica muestra la evolución hacia el largo plazo de la tasa de fondeo, de la tasa de CETES y de la diferencia entre ambas tasas.

Gráfica 4.4.a Efectos sobre las tasas de fondeo y de CETEs 28 y diferencia de estas tasas ante un "corto" de 20 millones de pesos

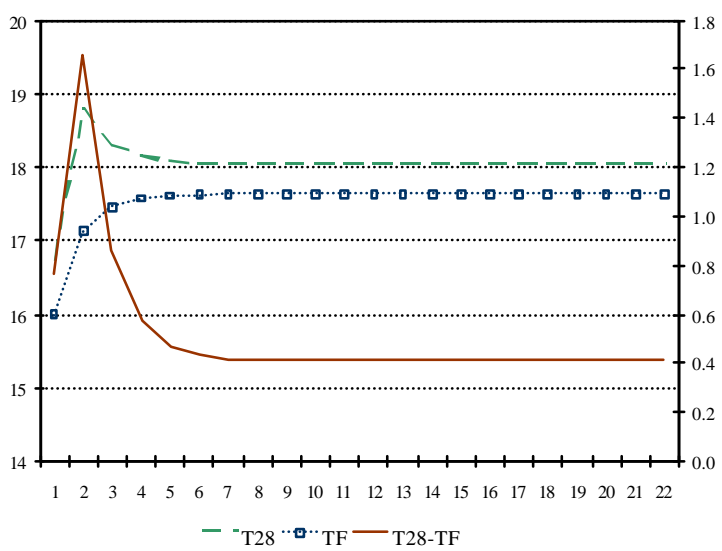

Gráfica 4.4.b Efectos sobre las tasas de fondeo y de CETEs 91 y diferencia de estas tasas ante un "corto" de 20 millones de pesos

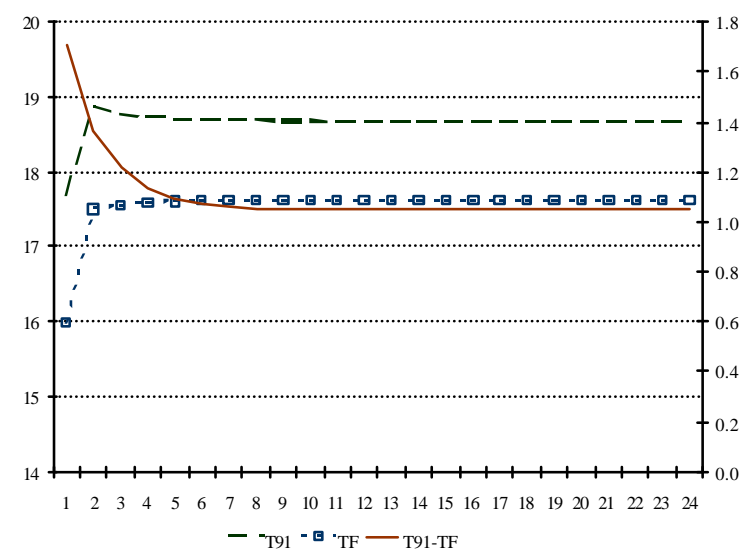


Gráfica 4.4.c Efectos sobre las tasas de fondeo y de CETEs 182 y diferencia de estas tasas ante un "corto" de 20 millones de pesos

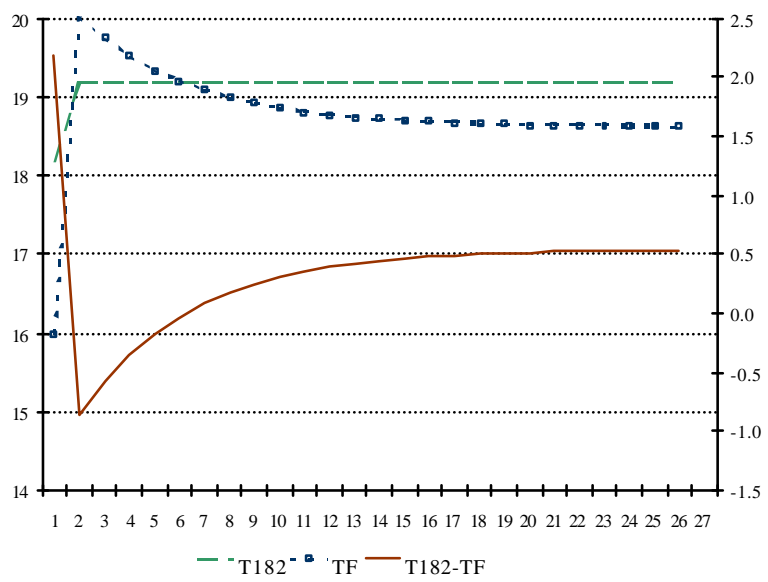

Gráfica 4.4.d Efectos sobre las tasas de fondeo y de CETEs 364 y diferencia de estas tasas ante un "corto" de 20 millones de pesos

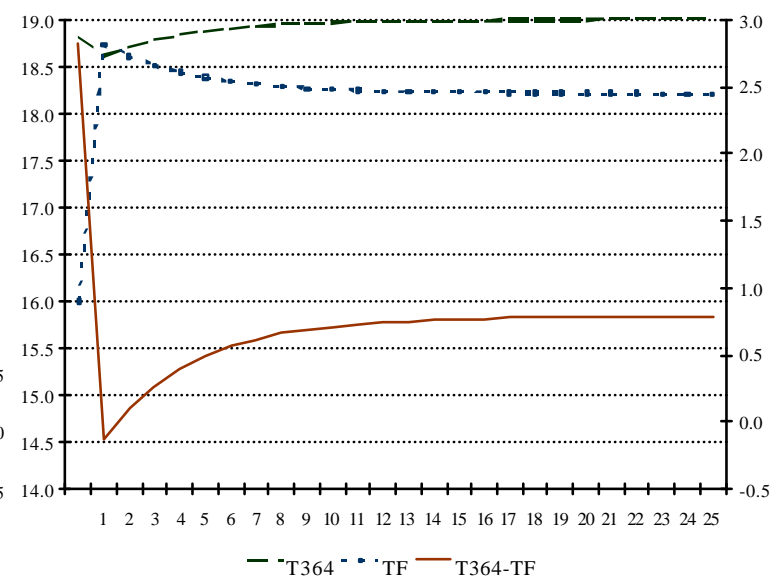

De acuerdo con estas gráficas, ante un "corto" de 20 millones de pesos, la diferencia con respecto a la tasa de fondeo que converge más rápidamente a su nivel de equilibrio de largo plazo es la asociada a la tasa de interés de los CETEs a 28 días (en aproximadamente 10 semanas), seguida de la de la tasa de 91 días (en aproximadamente 13 semanas), la de la tasa de 182 días (en aproximadamente 27 semanas) y, finalmente, la de la tasa de 364 días (en aproximadamente 36 semanas).

Las trayectorias de ajuste de las tasas en cada gráfica difieren en cada caso según el coeficiente asociado al término de error y el coeficiente asociado al "corto". Las trayectorias de las gráficas 4.4a y 4.4b, correspondientes a las tasas a 28 días y a 91 días respectivamente, son muy semejantes. Debido a que el efecto asociado al saldo objetivo es más grande en la tasa de CETES que en la tasa de fondeo, el "corto" genera un diferencial positivo entre ambas tasas. Asimismo, debido a que en ambos modelos de corrección de error los coeficientes asociados a este término son significativamente diferentes de cero, tanto la tasa de CETEs respectiva como la de fondeo cambian para restablecer la relación inicial: la tasa de CETEs baja y la tasa de fondeo sube. A pesar que el "corto" genera un diferencial de tasas con respecto a la tasa de fondeo mayor para la tasa de 28 días que para la tasa de 91 días, la velocidad de ajuste es mayor en el primer caso que en el segundo por lo que la convergencia al nuevo equilibrio es más rápida.

Las trayectorias de ajuste de las tasas de la gráfica 4.4c, correspondientes a la tasa de 182 días, difieren de las descritas anteriormente debido a que un "corto" tiene impacto sobre ambas tasas pero, en contraste con los dos casos previos, el diferencial que surge es de signo negativo debido a que ahora el impacto de mayor magnitud es sobre la tasa de fondeo. La otra diferencia proviene de que en este caso se observa que el coeficiente asociado al término de corrección de error en la ecuación de la tasa de más largo plazo no es significativamente distinto de cero, razón por lo que todo el ajuste hacia el nuevo equilibrio se lleva a cabo a través de ajustes de la tasa de fondeo. 
A su vez, las trayectorias de ajuste de las tasas de la gráfica $4.4 \mathrm{~d}$, correspondientes a la tasa de 364 días, difieren de todas las anteriores debido a que el coeficiente asociado al "corto" en la ecuación de la tasa de CETEs no es significativamente distinto de cero. Inicialmente el "corto" sólo tiene impacto sobre la tasa de fondeo, por lo que la tasa de fondeo alcanza un nivel superior inclusive al de la tasa de CETEs y surge un diferencial entre las tasas con signo negativo. Es a través de este diferencial que ambas tasas comienzan a ajustarse hacia el equilibrio de largo plazo, mediante aumentos en la tasa de CETEs y reducciones en la de fondeo.

Para apreciar el efecto del "corto" de 20 millones de pesos sobre la curva de tasas de interés una, dos y tres semanas después del anuncio tomamos los valores provenientes del modelo para esos tres periodos. El aplanamiento de esta curva en respuesta al "corto" que muestran los modelos de corrección de error estimados se aprecia en la gráfica 4.5. Este aplanamiento es mayor después de la primera semana porque el modelo predice un efecto mayor sobre las tasas de interés de CETES a 28 y 91 días y un efecto menor ó prácticamente nulo sobre la tasa de interés de 364 días.

\section{Gráfica 4.5 Efecto de un "corto" de 20 millones de pesos sobre la curva de tasas de} interés de los CETEs

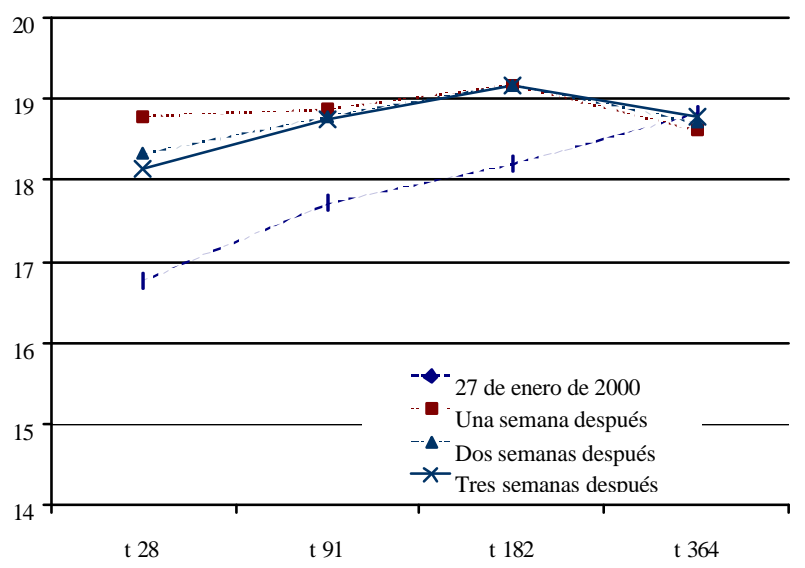




\section{Extensiones y Conclusiones}

La estimación a través de MCO del modelo para la tasa de interés de fondeo en el periodo de análisis presenta problemas de estabilidad en los parámetros y la presencia de efectos de heteroscedasticidad condicional en los residuales. Probablemente una muestra de 4 años, aunque tenga periodicidad diaria, no es suficiente para captar todas las características de las variables que nos interesan. Será interesante emplear análisis de eventos o métodos no paramétricos en estudios futuros que tienen mejores propiedades con muestras pequeñas. Algunas estimaciones que hemos realizado en esta dirección confirman que la efectividad del "corto" varía dramáticamente en los diferentes episodios analizados.

Con base en el análisis de regresiones "rodantes" encontramos un efecto sobre la tasa de fondeo asociado al "corto" que es de menor magnitud que la que reportan estudios previos. Este efecto presenta cierta inestabilidad durante 1998. Este análisis también indica que en el periodo de análisis el efecto de la depreciación del tipo de cambio es positivo y tiene una tendencia decreciente, en tanto que aquél del diferencial de tasas entre el bono Brady de México y el bono de Estados Unidos a 30 años es positivo y estable a partir de 1999. Asimismo, tampoco se observa una correlación positiva entre la tasa de fondeo y la tasa del bono a 30 años de Estados Unidos probablemente debido al aumento en la aversión al riesgo y en la preferencia por la liquidez que se dio durante la crisis financiera internacional de 1998.

En este modelo hemos supuesto implícitamente que las variables explicativas que utilizamos son independientes. Sin embargo, en la sección 3.4 se presenta evidencia de que este supuesto puede no ser del todo adecuado. Por tanto, será deseable especificar modelos que permitan simultaneidad, especialmente en la determinación del tipo de cambio y del objetivo de saldo acumulado.

Los resultados de la sección 4 confirman una relación de cointegración entre la tasa de fondeo y las tasas de interés de los CETEs en la que los choques en la primera se corrigen con mayor velocidad en las tasas de más corto plazo que en las de más largo plazo. Será deseable modelar explícitamente la relación de largo plazo entre las tasas de interés con otros métodos más poderosos en el futuro. Mientras tanto, a través de modelos de corrección de error encontramos que el "corto" tiene un mayor efecto en las tasas de CETEs de más corto plazo que en las tasas de CETEs de más largo plazo. Este resultado sugiere que la política restrictiva en el corto plazo mediante el "corto" reduce las expectativas de inflación futura.

En conclusión, adquirir un mejor entendimiento del primer eslabón del mecanismo de transmisión de la política monetaria de México requerirá de más estudios. Es especialmente deseable que éstos empleen metodologías distintas que permitan tanto captar otros aspectos de los datos como verificar la bondad de estas estimaciones. 


\section{Bibliografía}

Aguilar, A. y V. H. Juan-Ramón (1997), "Determinantes de las tasas de interés de corto plazo en México: efecto de las señales del banco central", Gaceta de Economía, ITAM, No. 5 .

Campbell, J. Y. (1996), “Understanding Risk and Return”, Journal of Political Economy, Vol 104, No. 2.

Campbell, J. Y. y L. Hentschel (1991), "No News is Good News: An Asimmetric Model of Changing Volatility in Stock Returns", NBER Working Paper Series No. 3742.

Campbell, J. Y. y L. Hentschel (1992), "No News is Good News: An Asimmetric Model of Changing Volatility in Stock Returns", Journal of Financial Economics 31.

Carstens, A. G. y A. M. Werner (1999), “Mexico's Monetary Policy Framework under a Floating Exchange Rate Regime", Serie de Documentos de Investigación del Banco de México, Número 9905.

Deutsch, M., C. Granger y T. Teräsvirta, "The Combination of Forecasts Using Changing Weights" International Journal of Forecasting 10, 1994.

Enders, W. (1995), "Applied Econometric Time Series", Wiley Series in Probability and Mathematical Statistics, John Wiley \& Sons, Inc, USA.

Escrivá, J. L. Y G. P. Fagan (1996), “Empirical Assessment of Monetary Policy Instruments and Procedures (MPIP) in EU Countries", European Monetary Institute Staff Paper No. 2.

Fleming, M. J. y E. M. Remolona (1997), “What Moves the Bond Market?”, FRBNY Economic Policy Review, Diciembre 1997.

Gil, F. (1997), "La política monetaria y sus canales de transmisión en México", Gaceta de Economía, ITAM, No. 5.

Gil, F. (1998), "Monetary policy and its transmission mechanism in Mexico", in The Transmission of Monetary Policy in Emerging Economies, Bank for International Settlements, Basle, 1998.

Glosten, L. R., Jagannathan, R. y D. E. Runkle (1993), “On the Relation between the Expected Value and the Volatility of the Nominal Excess Return on Stocks", Journal of Finance, Vol. XLVIII, No. 5. 
Green, W. H. (1993), "Econometric Analysis", MacMillan Publising Company, New York, Second Edition.

Greenham, L. (1997), “Mecanismo de Transmisión de Política Monetaria en México”, Tesis de Licenciatura en Economía, ITAM.

Harrison, P. y H. H. Zhang (1995), “An Investigation of the Risk and Return Relation at Long Horizon", mimeógrafo.

Intriligator, M. D., Bodkin, R. y C. Hsiao (1978), "Econometric Models, Techniques and Applications", Prentice-Hall Inc, Second Edition.

Informe Anual de Política Monetaria, Banco de México, varios números.

Nelson, D. B. (1991), "Conditional Heteroskedasticity in Asset Returns: A New Approach", Econometrica, Vol 59, No. 2.

O’Dogherty, P. (1997), “La instrumentación de la política monetaria por el banco central”, Gaceta de Economía, ITAM, No. 5.

Schwartz, M. (1998), "Consideraciones sobre la Instrumentación Práctica de la Política Monetaria", Serie de Documentos de Investigación del Banco de México, Número 9804.

Wasserfallen, W. y G. Kürsteiner (1994), “Interest rates and exchange rates under money supply targets”, Journal of Monetary Economics 33, 201-230. 


\section{Apéndice}

Cuadro A.1 Comparación de resultados propios (efectos totales ${ }^{*}$ ) con los de Aguilar y Juan-Ramón (1997)

\begin{tabular}{c|rc|cc}
\hline & \multicolumn{2}{|c|}{ Aguilar y Juan Ramón } & \multicolumn{2}{c}{ Resultados propios } \\
\cline { 2 - 5 } & $9 / 13 / 95-3 / 14 / 96$ & $3 / 14 / 96-12 / 24 / 96$ & $9 / 13 / 95-3 / 14 / 96$ & $3 / 14 / 96-12 / 24 / 96$ \\
\hline C & & -11.39 & & \\
SOBJ & -7.14 & -9.05 & -0.063435 & -0.084272 \\
TC & 2338 & 1993 & 25.23152 & 21.961171 \\
B30 & & & & \\
\hline & $\mathrm{R}^{2}=0.69$ & $\mathrm{R}^{2}=0.30$ & $\mathrm{R}^{2}=0.745339$ & $\mathrm{R}^{2}=0.297797$ \\
& $\mathrm{R}^{2}$ Ajustada=0.66 & $\mathrm{R}^{2}$ Ajustada=0.27 & $\mathrm{AR}^{2}=0.717043$ & $\mathrm{AR}^{2}=0.253909$ \\
& & & $\mathrm{AIC}=0.715469$ & $\mathrm{AIC}=-0.469729$ \\
& & & $\mathrm{SBC}=1.000284$ & $\mathrm{SBC}=-0.267633$ \\
& & & Total obs 101 & Total obs 171 \\
\hline
\end{tabular}

*El efecto total es igual a la suma de los parámetros de las variables rezagadas significativas al 90\% o más.

Cuadro A.2 Comparación de resultados propios (efectos totales ${ }^{\ddagger}$ ) con los de Greenham (1997)

\begin{tabular}{|c|c|c|}
\hline & Greenham & $7 \quad$ Resultados propios \\
\hline & & $\Delta($ Fondeo $)$ \\
\hline $\mathrm{C}$ & -0.0913 & \\
\hline SOBJ & -0.0936 & -0.074123 \\
\hline TC & 22.3175 & 25.23770 \\
\hline B30 & 1.3097 & \\
\hline & & $\begin{array}{c}\mathrm{R}^{2}=0.284728 \\
\mathrm{R}^{2} \text { Ajustada }=0.271384 \\
\text { AIC }=-0.344718 \\
\mathrm{SBC}=-0.265598 \\
\text { Total obs } 274\end{array}$ \\
\hline
\end{tabular}

${ }^{\ddagger}$ El efecto total es igual a la suma de los parámetros de las variables rezagadas significativas al $90 \%$ o más 
Cuadro A.3 Pruebas de Autocorrelación Breusch-Godfrey LM de la Regresión C

\begin{tabular}{cccc}
\hline Rezagos & Estadístico $\mathrm{F}$ & (\# de observaciones)* $\mathrm{R}^{2}$ \\
\hline 1 & 3.15666 & 3.48153 & \\
3 & 1.39095 & 4.61228 & \\
5 & 3.85173 & 18.75826 & $*$ \\
7 & 0.93051 & 7.22593 & \\
9 & 1.74760 & 17.17467 & $* * *$ \\
11 & 1.49433 & 17.99959 & $* * *$ \\
13 & 1.58500 & 22.45684 & $* * *$ \\
15 & 1.45657 & 23.85139 & $* * *$ \\
\hline
\end{tabular}

"Significativo al 1\%, ${ }^{* *}$ significativo al $5 \%,{ }^{* * *}$ significativo al $10 \%$

\subsubsection{Cuadro A.4 Pruebas de Heteroscedasticidad Arch LM} de la Regresión C

\begin{tabular}{|c|c|c|c|c|}
\hline Rezagos & Estadístico F & & (\# de observaciones) $* \mathrm{R}^{2}$ & \\
\hline 1 & 16.12327 & & 15.68122 & \\
\hline 3 & 6.30397 & & 18.36316 & \\
\hline 5 & 3.85173 & & 18.75826 & \\
\hline 7 & 3.47282 & & 23.53437 & * \\
\hline 9 & 2.94223 & & 25.62354 & \\
\hline 11 & 2.54978 & & 27.15996 & \\
\hline 13 & 2.19626 & & 27.72634 & \\
\hline 15 & 1.89083 & & 27.66040 & \\
\hline
\end{tabular}




\section{Cuadro A.5 Pruebas de estabilidad de los parámetros de la Regresión C}

a) Residuales recursivos

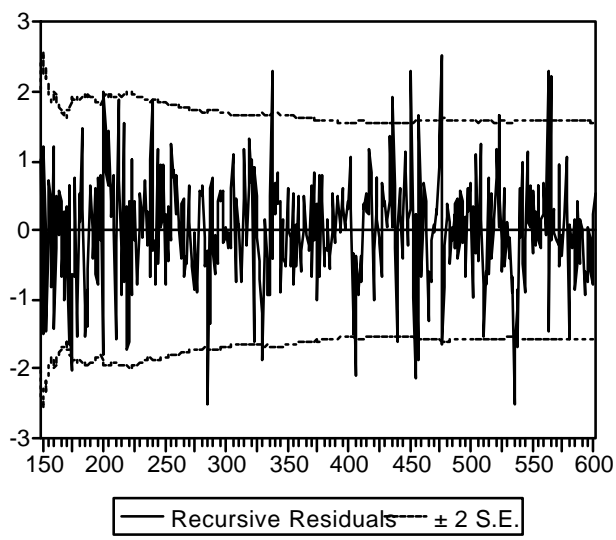

c) CUSUM $^{2}$

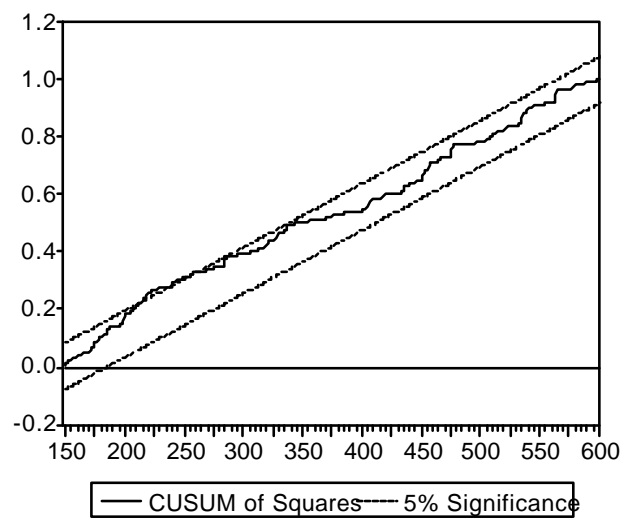

b) CUSUM

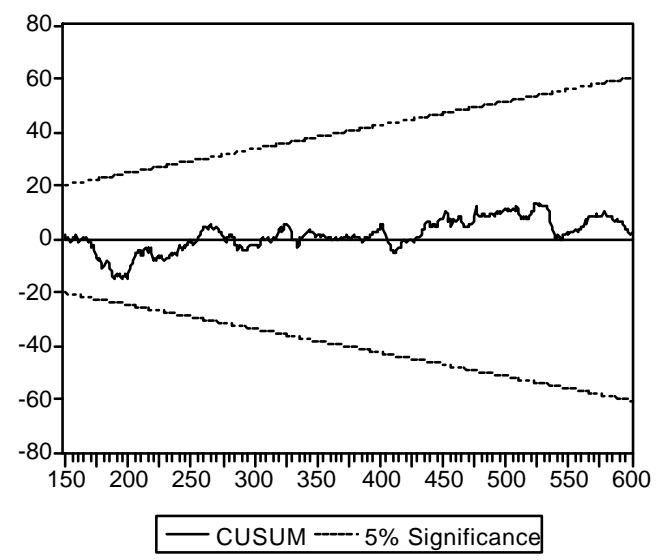

d) Prueba de pronóstico a un paso

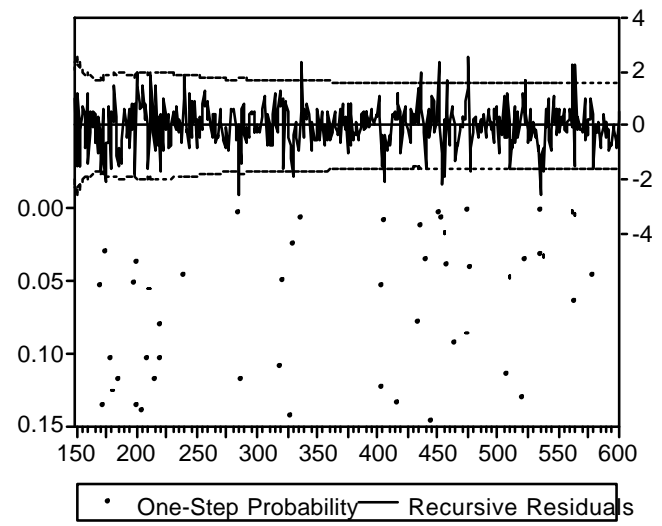

e) Prueba de pronóstico a un paso

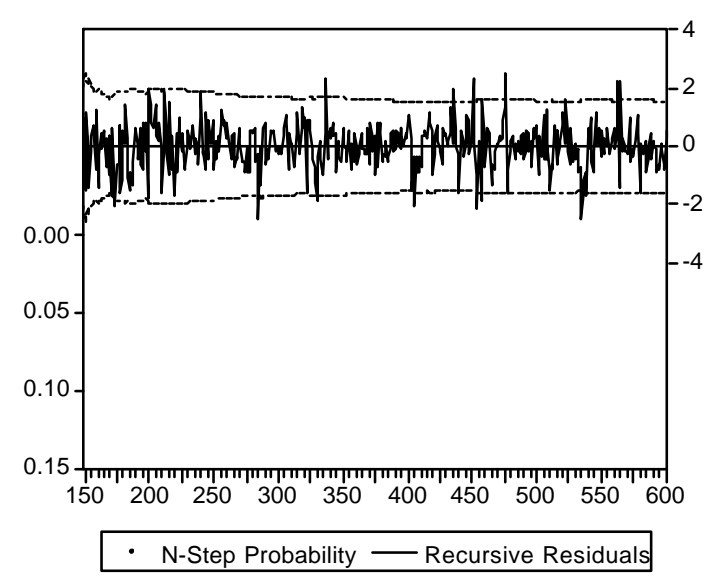


Cuadro A.6 Prueba de Estabilidad de Coeficientes Recursivos Estimados de la Regresión C

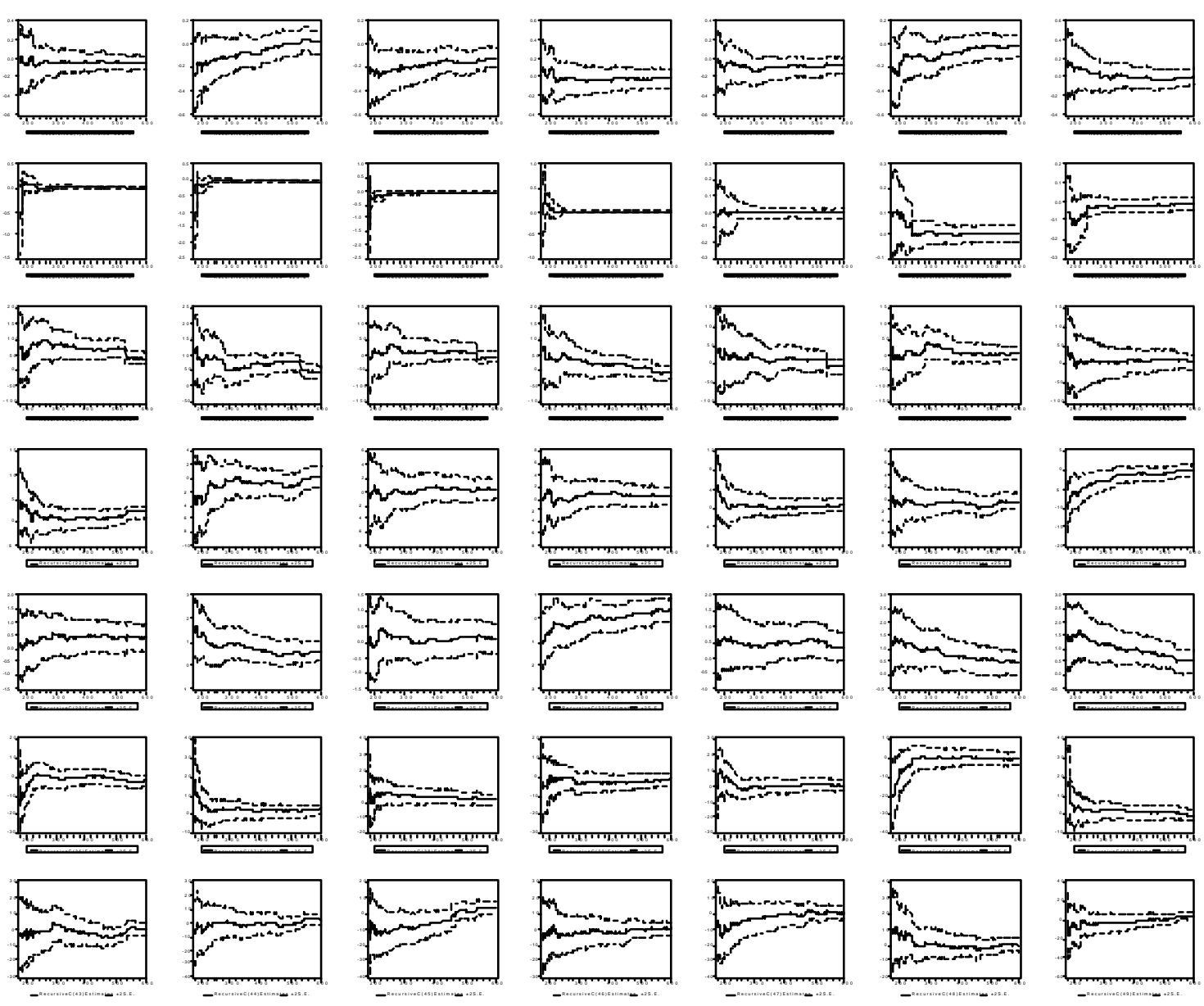


Cuadro A.7 VAR 1:

Tasa de fondeo - Tipo de cambio - Saldo objetivo

(9/19/1995t-01/31/2000, 1054 observaciones)

\begin{tabular}{|c|c|c|c|}
\hline & $\mathrm{F}$ & $\mathrm{TC}$ & $\mathrm{SO}$ \\
\hline TFON(t-1) & $0.68057^{*}$ & -0.00026 & -0.10453 \\
\hline TFON(t-2) & $0.22407^{*}$ & $0.00006^{*}$ & $0.56979^{*}$ \\
\hline TFON(t-3) & -0.02339 & $0.00013^{*}$ & $1.00020^{* *}$ \\
\hline TFON(t-4) & $-0.00195^{* *}$ & 0.00000 * & -0.97595 \\
\hline TFON(t-5) & 0.10334 & $0.00000^{* *}$ & $-0.07212^{*}$ \\
\hline TFON(t-6) & $-0.08391^{*}$ & -0.00036 & 0.38613 \\
\hline TFON(t-7) & $0.01950^{* * *}$ & $0.00001 *$ & $0.60287^{* *}$ \\
\hline TFON(t-8) & $0.01863^{*}$ & -0.00013 & $-1.30907^{* * *}$ \\
\hline $\mathrm{TC}(\mathrm{t}-1)$ & $52.64702^{*}$ & $0.94132^{*}$ & $-143.17919^{*}$ \\
\hline $\mathrm{TC}(\mathrm{t}-2)$ & $-57.76599^{*}$ & $-0.11086^{*}$ & $71.34983^{* *}$ \\
\hline $\mathrm{TC}(\mathrm{t}-3)$ & 13.35552 * & 0.19744 & $-123.78831^{* * *}$ \\
\hline $\mathrm{TC}(\mathrm{t}-4)$ & 14.63871 & $-0.07860^{*}$ & 159.81072 \\
\hline $\mathrm{TC}(\mathrm{t}-5)$ & -12.98285 & $0.03837^{*}$ & $-156.09454^{* *}$ \\
\hline $\mathrm{TC}(\mathrm{t}-6)$ & -13.64743 & $-0.17759^{*}$ & 111.31136 \\
\hline $\mathrm{TC}(\mathrm{t}-7)$ & $8.48069^{*}$ & $0.16078^{*}$ & $146.18505^{*}$ \\
\hline $\mathrm{TC}(\mathrm{t}-8)$ & $-5.68121^{* *}$ & 0.01722 & $-82.23525^{*}$ \\
\hline $\operatorname{SOBJ}(\mathrm{t}-1)$ & $-0.04248^{*}$ & -0.00001 & $1.00858^{*}$ \\
\hline $\operatorname{SOBJ}(\mathrm{t}-2)$ & $0.00088^{*}$ & $-0.000001^{*}$ & $-0.27903^{* *}$ \\
\hline $\operatorname{SOBJ}(\mathrm{t}-3)$ & 0.01390 ** & $-0.00003^{* *}$ & -0.29740 \\
\hline $\operatorname{SOBJ}(\mathrm{t}-4)$ & 0.01815 & -0.000001 & 0.53273 \\
\hline $\operatorname{SOBJ}(\mathrm{t}-5)$ & $-0.01266^{*}$ & -0.00001 & $-0.16428^{*}$ \\
\hline $\operatorname{SOBJ}(\mathrm{t}-6)$ & 0.00698 & -0.000001 & -0.03622 \\
\hline $\operatorname{SOBJ}(\mathrm{t}-7)$ & $0.00512^{*}$ & $-0.000001^{*}$ & $0.19388^{*}$ \\
\hline $\operatorname{SOBJ}(\mathrm{t}-8)$ & 0.01151 & $-0.000001^{* *}$ & 0.00547 \\
\hline $\mathrm{C}$ & $5.51381^{*}$ & $0.05598^{*}$ & 44.06498 \\
\hline Spread & $0.14664^{*}$ & 0.00127 & $-0.61575^{* *}$ \\
\hline B30 & $-0.03474^{* * *}$ & $-0.00177^{*}$ & -0.55624 \\
\hline LBRA & $-0.29682^{*}$ & -0.00178 & $-0.56318^{*}$ \\
\hline $\mathrm{R}^{2}$ & 0.98202 & 0.99693 & 0.98538 \\
\hline $\mathrm{R}^{2}$ Ajustada & 0.98154 & 0.99685 & 0.98500 \\
\hline AIC & 3.21391 & -7.30530 & 7.07177 \\
\hline SBC & 3.34569 & -7.17352 & 7.20354 \\
\hline
\end{tabular}




\section{Cuadro A.8 VAR 2:}

Tipo de cambio - Tasa de fondeo - Saldo objetivo (9/19/1995t-01/31/2000, 1057 observaciones)

\begin{tabular}{|c|c|c|c|}
\hline & $\mathrm{TC}$ & TFON & SOBJ \\
\hline $\mathrm{C}$ & 0.05548 & 5.82178 & 28.61271 \\
\hline $\mathrm{TC}(\mathrm{t}-1)$ & 0.94211 & 51.78456 & -167.56995 \\
\hline $\mathrm{TC}(\mathrm{t}-2)$ & -0.11376 & -58.18249 & 112.45097 \\
\hline $\mathrm{TC}(\mathrm{t}-3)$ & 0.20373 & 15.30345 & -146.83456 \\
\hline $\mathrm{TC}(\mathrm{t}-4)$ & -0.08063 & 13.19158 & 192.32095 \\
\hline TC(t-5) & 0.04125 & -13.05153 & -188.56311 \\
\hline $\mathrm{TC}(\mathrm{t}-6)$ & -0.18547 & -16.37690 & 130.14303 \\
\hline TC(t-7) & 0.18115 & 6.43009 & 54.72663 \\
\hline TFON(t-1) & -0.00023 & 0.68889 & -0.13926 \\
\hline TFON(t-2) & 0.00011 & 0.23148 & 0.75038 \\
\hline TFON(t-3) & -0.00001 & -0.03403 & 0.99923 \\
\hline TFON(t-4) & -0.00001 & 0.00028 & -1.07584 \\
\hline TFON(t-5) & -0.00001 & 0.11491 & -0.10727 \\
\hline TFON(t-6) & -0.00038 & -0.06891 & 0.24260 \\
\hline TFON(t-7) & -0.00001 & 0.00300 & -0.53390 \\
\hline $\operatorname{SOBJ}(\mathrm{t}-1)$ & -0.00001 & -0.04105 & 1.02039 \\
\hline $\operatorname{SOBJ}(\mathrm{t}-2)$ & -0.00001 & 0.00056 & -0.29949 \\
\hline $\operatorname{SOBJ}(\mathrm{t}-3)$ & -0.00001 & 0.01255 & -0.25561 \\
\hline $\operatorname{SOBJ}(\mathrm{t}-4)$ & -0.00001 & 0.02283 & 0.54107 \\
\hline $\operatorname{SOBJ}(\mathrm{t}-5)$ & -0.00001 & -0.01563 & -0.18163 \\
\hline $\operatorname{SOBJ}(\mathrm{t}-6)$ & -0.000001 & 0.00472 & -0.02431 \\
\hline $\operatorname{SOBJ}(\mathrm{t}-7)$ & -0.00001 & 0.01725 & 0.16924 \\
\hline Spread & 0.00125 & 0.14624 & -0.56714 \\
\hline B30 & -0.00175 & -0.03824 & -0.20520 \\
\hline LBRA & -0.00181 & -0.33649 & 0.00507 \\
\hline $\mathrm{R}^{2}$ & 0.99695 & 0.98189 & 0.98460 \\
\hline $\mathrm{R}^{2}$ Ajustada & 0.99688 & 0.98146 & 0.98424 \\
\hline AIC & -7.31140 & 3.21493 & 7.12142 \\
\hline SBC & -7.19401 & 3.33232 & 7.23881 \\
\hline
\end{tabular}


Cuadro A.9 Pruebas de Heteroscedasticidad

Arch LM de los modelos de corrección de error.

\begin{tabular}{|c|c|c|}
\hline Número de rezagos & Estadístico F & (\# de observaciones)* $\mathbf{R}^{2}$ \\
\hline \multicolumn{3}{|c|}{ Panel A: Tasas de fondeo y de 27 días } \\
\hline \multicolumn{3}{|c|}{ Variable dependiente: $\Delta \mathrm{T} 27$} \\
\hline 1 & $3.5925^{* * * *}$ & 3.5521 \\
\hline 2 & 2.0140 & 3.9981 \\
\hline 3 & 1.4443 & 4.3223 \\
\hline \multicolumn{3}{|c|}{ Variable dependiente: $\Delta \mathrm{TFON}$} \\
\hline 1 & 1.336238 & 1.342022 \\
\hline 2 & 0.816060 & 1.647242 \\
\hline 3 & $2.847750^{* *}$ & $8.281952^{* *}$ \\
\hline \multicolumn{3}{|c|}{ Panel B: Tasas de fondeo y de 91 días } \\
\hline \multicolumn{3}{|c|}{ Variable dependiente: $\Delta \mathrm{T} 91$} \\
\hline 1 & 0.0084 & 0.0085 \\
\hline 2 & 1.2176 & 2.4456 \\
\hline 3 & 0.8037 & 2.4407 \\
\hline \multicolumn{3}{|c|}{ Variable dependiente: $\Delta \mathrm{TFON}$} \\
\hline 1 & 2.356311 & 2.350764 \\
\hline 2 & 1.319476 & 2.645494 \\
\hline 3 & $2.946212^{* * *}$ & 8.545388 \\
\hline \multicolumn{3}{|c|}{ Panel C: Tasas de fondeo y de 182 días } \\
\hline \multicolumn{3}{|c|}{ Variable dependiente: $\Delta \mathrm{T} 182$} \\
\hline 1 & 0.0374 & 0.0381 \\
\hline 2 & 0.5265 & 1.0722 \\
\hline 3 & 0.3662 & 1.1297 \\
\hline \multicolumn{3}{|c|}{ Variable dependiente: $\Delta \mathrm{TFON}$} \\
\hline 1 & $3.2250^{* * *}$ & 3.1878 \\
\hline 2 & 2.0239 & 4.0059 \\
\hline 3 & 1.6637 & 4.9396 \\
\hline \multicolumn{3}{|c|}{ Panel D: Tasas de fondeo y de 364 días } \\
\hline \multicolumn{3}{|c|}{ Variable dependiente: $\Delta \mathrm{T} 364$} \\
\hline 1 & 0.3106 & 0.3155 \\
\hline 2 & 0.2336 & 0.4787 \\
\hline 3 & 0.3637 & 1.1233 \\
\hline \multicolumn{3}{|c|}{ Variable dependiente: $\Delta$ TFON } \\
\hline 1 & $5.6947^{* *}$ & $5.4937^{* * *}$ \\
\hline 2 & 3.2958 ** & $6.3515^{* *}$ \\
\hline 3 & $2.8401^{* *}$ & $8.1171^{* *}$ \\
\hline
\end{tabular}

${ }^{*}$ Significativo al 1\%. ${ }^{* *}$ Significativo al 5\%. ${ }^{* * *}$ Significativo al $10 \%$. 